\title{
Concentrating solar power tower technology: present status and outlook
}

https://doi.org/10.1515/nleng-2017-0171

Received December 19, 2017; accepted February 21, 2018.

\begin{abstract}
The paper examines design and operating data of current concentrated solar power (CSP) solar tower (ST) plants. The study includes CSP with or without boost by combustion of natural gas (NG), and with or without thermal energy storage (TES). Latest, actual specific costs per installed capacity are high, 6,085 \$/kW for Ivanpah Solar Electric Generating System (ISEGS) with no TES, and 9,227 \$/kW for Crescent Dunes with TES. Actual production of electricity is low and less than the expected. Actual capacity factors are $22 \%$ for ISEGS, despite combustion of a significant amount of $\mathrm{NG}$ exceeding the planned values, and 13\% for Crescent Dunes. The design values were 33\% and $52 \%$. The study then reviews the proposed technology updates to improve ratio of solar field power to electric power, capacity factor, matching of production and demand, plant's cost, reliability and life span of plant's components. Key areas of progress are found in materials and manufacturing processes, design of solar field and receiver, receiver and power block fluids, power cycle parameters, optimal management of daily and seasonal operation of the plant, new TES concepts, integration of solar plant with thermal desalination or combined cycle gas turbine (CCGT) installations and specialization of project.
\end{abstract}

Keywords: renewable energy; concentrated solar power; solar tower; parabolic trough; natural gas boost; thermal energy storage; molten salt; steam; Rankine cycles

\footnotetext{
*Corresponding Author: Albert Boretti, Department of Mechanical and Aerospace Engineering (MAE), Benjamin M. Statler College of Engineering and Mineral Resources, West Virginia University, Morgantown, WV 26506, United States, E-mail: alboretti@mail.wvu.edu, a.a.boretti@gmail.com

Stefania Castelletto, School of Engineering, RMIT University, Bundoora, VIC 3083, Australia, E-mail: stefania.castelletto@rmit.edu.au Sarim Al-Zubaidy, The University of Trinidad and Tobago, Trinidad and Tobago, E-mail: sarim.alzubaidy@gmail.com
}

\section{Introduction}

The basic principles of concentrated solar power (CSP) systems are covered in previous reference works such as [15]. Lenses or mirrors concentrate the sun light energy on a small area. The concentrated radiant energy is then converted to heat at high temperature. The heat is finally transferred to a power cycle working fluid (typically water/steam). Superheated steam typically drives a Rankine steam turbine cycle. Concentrators differ in the way they track the sun and focus the light. The most popular concentrating technologies are Parabolic Trough (PT) and Solar Tower (ST). Different concentrators provide different receiver temperature and peak temperature of the steam for the power cycle, with correspondingly varying thermal efficiency of the power cycle. In addition to the type of receiver and the solar field feeding this receiver, also the receiver fluid (RF) plays a role in the peak temperatures of the steam. Current RFs include oil, molten salt (MS) or water/steam. Intermediate heat exchangers are needed between oil or MS and water/steam. MS permits thermal energy storage (TES) in hot and cold reservoir to decouple electricity production from availability of sun light. While an additional MS circuit has been proposed as an appendage to existing CSP plants with oil as RF, MS provides better outcome when used directly as the RF. Replacement of oil with MS permits operation at higher temperatures for higher steam temperature and higher efficiency of power generation. Additionally, it lowers the cost of TES. Direct use of water/steam as a RF has the advantage of simplicity, cost and sometimes efficiency. However, this links the production of electricity to sun availability. Condensation of steam usually occurs in air-cooled towers. Water cooled condensers may permit better power cycle efficiencies but are impractical in mostly desert locations.

By using the combustion of natural gas (NG), it is possible to drastically improve the match between production and demand of CSP plants. However, boost by NG is reasonable only if performed in minimal extent, for both efficiency of energy use and regulations concerning emissions of carbon dioxide. The use of NG in a combined cycle gas turbine (CCGT) plant occurs with a fuel conversion efficiency that is about double the efficiency of a CSP plant op- 
erated with NG only ( $\eta$ above $60 \%$ vs. $\eta$ around $30 \%$ ). The spreading in between the $\eta$ of a CSP plant and a NG fueled plant is similarly large in cases of cogeneration, where the gas turbine (GT) plant also features production of process heat, for heating, cooling, desalination or other activities. Therefore, it is not efficient to design a CSP ST plant requiring a significant NG combustion.

The ST technology offers theoretically higher efficiency because of higher temperature. However, the technology is also more demanding from economic and technical view-points. While ST plants are certainly less widespread than PT plants [6], there is an open debate in the literature about which CSP technology may have the better perspectives.

The world largest CSP plant, Ivanpah Solar Electric Generating System (ISEGS) uses ST technology. ISEGS is made up of three installations one close to the other. The second largest CSP project in the world, the Solar Energy Generating Systems (SEGS) facility, is based on PT. This project is made up of 8 different installations presently operational. The net capacity of ISEGS is 377 MW, while the net capacity of Solar Energy Generating Systems (SEGS) SEGS II-IX is $340 \mathrm{MW}$. Both facilities use NG to boost the electricity production. ISEGS uses NG in a greater extent than the SEGS facilities. Both ISEGS and SEGS lack of TES. The actual capacity factors $(\epsilon)$ of both installations (electricity produced in a year divided by the product of net capacity by number of hours in a year) is about $20 \%$ disregarding the boost by combustion of NG, which is however not negligible as shown in [8] and here further discussed.

The global market of CSP is dominated by PT plants, about $90 \%$ of all the CSP plants [6]. As per [6], back in 2010 the ST component of CSP was overshadowed by the PT component, accounting for more than $90 \%$ of the total CSP installed capacity. The situation has not drastically changed since then [7]. The majority of the larger CSP plant projects under development/under construction are based on the solar tower configuration.

The CSP technologies presently do not compete on price with photovoltaics (PV) solar panels that have progressed massively in recent years because of the decreasing prices of the $\mathrm{PV}$ panels and the much smaller operating costs. While the uptake of solar energy is still minimal, the CSP component is largely overshadowed by the PV component [9]. While CSP may have the potential to play a key role in balancing renewable energy production, the technology is presently living in the shadow of PV [9].

Both installed capacity (power) and electricity production (energy) data show the CSP ST technology is overshadowed by the CSP PT technology, while overall the CSP technology suffers from the more competitive costs of PV, while the total solar contribution to the global energy mix is still minimal [6, 7, 9-11]. According to [7], in 2016 globally only wind and solar PV power systems have seen a considerable growth in terms of capacity installed compared to 2015 data. In 2016 globally the hydropower capacity has been 1,096 GW (in 2015 1,071 GW), the bio-power capacity has been $112 \mathrm{GW}$ (in $2015106 \mathrm{GW}$ ), the geothermal power capacity has been $13.5 \mathrm{GW}$, (in $201513 \mathrm{GW}$ ), the CSP capacity has been $4.8 \mathrm{GW}$ (in $20154.7 \mathrm{GW}$ ). Conversely in 2016 the global wind power capacity has been $487 \mathrm{GW}$, more than $10 \%$ higher than the year before $(433 \mathrm{GW})$ and the global solar PV capacity has been $303 \mathrm{GW}$, almost 40\% more than the 2015 value of $228 \mathrm{GW}$. The installed capacity of CSP is only about $1.5 \%$ of the total solar power capacity, where the installed capacity of $\mathrm{PV}$ is $98.5 \%$ of the total solar power capacity.

As explained in Ref. [8], the installed capacity (power) is particularly misleading in case of solar if used to indicate the actual annual production of electricity (energy) by these systems, as the capacity factors (electricity produced divided by the product of the installed capacity by the number of hours in a year) of recent CSP plants, for example ISEGS [12-15], are only about $20 \%$, even conceding the benefit of a production boost by combustion of NG.

In terms of energy, according to the International Energy Agency [10], the 2014 World electricity generation has been 23,816 TWh, with Coal/Peat providing the $40.8 \%$, NG the $21.6 \%$, Hydro the $16.4 \%$, Nuclear the $10.6 \%$, Oil the $4.3 \%$, and Others, including all the Renewables the $6.3 \%$. This $6.3 \%$ is mostly wind. Presently, the total solar electricity generation in the world is only $1.05 \%$ of the total. According to the United States Energy Information Administration [11], the net generation in the United States during 2015 has been $31.2 \%$ by coal, $34.7 \%$ by NG, $20.2 \%$ nuclear, $6.7 \%$ by conventional hydroelectric, $5.7 \%$ by wind, and $1.4 \%$ all solar. As CSP plants only represent $1.5 \%$ of the worldwide installed capacity of solar electricity plants, the total CSP contribution to the global energy mix is therefore less than $0.02 \%[7,10]$. The situation in the United States is not far from the world average. The contribution by CSP ST is then an even smaller $0.002 \%$.

This scenario is expected to drastically change in the next few years, and there is a clear need to develop new CSP ST technologies to match the significant demand. However, this requires significant technology updates that is unclear could be delivered.

Ref. [16] discusses the most relevant drivers and barriers for the deployment of CSP in the EU by 2030. Apart from supporting policies, the most relevant drivers are the added value of CSP in terms of energy storage that makes them more reliable compared to other renewable energy 
technologies, and the substantial cost reductions that are expected for the technology. The most relevant barriers are the still very high cost of the technology when compared to conventional power plants and other renewable energy technologies, and the uncertainty of policies. Hence, reduction of costs of the CSP technology is the key factor for a growth. Similarly, Ref. [17] discusses the main reasons why Chinese and Brazilian energy policies so far have not been focused on CSP. As the high Levelized Cost of Electricity (LCOE) of large scale deployment of CSP technologies may affect the competitiveness of national industry in global markets, a comprehensive answer may only follow global policies. CSP has not benefited so far from the global demand that has boosted wind and solar photovoltaic with their subsequent price reductions.

Aims of this paper are to provide an objective assessment of the current costs and performances of CSP ST plants, and then to survey the proposed technologies the many issues that strongly limit the current outlook of CSP ST. As the present costs and performances differ considerably from the planned values, this negatively impacts on the reliability of the figures circulated in the surveyed peer review works.

\section{Methods}

The specific renewable energy technology assessment is performed based on actual costs and electricity production data of existing power plants delivering electricity to the grid and having a nameplate capacity exceeding a threshold value.

The survey of development trends is then performed based on a review of the latest literature that propose advances vs. the current design. These literature claims may not translate in actual technology improvements as asserted in the papers.

\section{Assessment of present status of CSP ST technology}

Concentrating solar power (CSP) has been so far mostly proposed and implemented in the parabolic through (PT) technology. 90\% of the CSP plants are indeed PT. Hence, we start this state-of-the-art paragraph with a reference to the PT technology to move then to the ST technology. Incidents and accidents are not considered in the present analysis, similarly to the environmental impacts. The substan- tial land requirements for CSP are also not included in the analysis.

\subsection{List of CSP ST plants}

The number of existing CSP ST plants of significant size is very limited, and the time they have been operational is also minimal. Additionally, not all the data needed are publicly available. Hence, the full potential of the ST technology is not shown by the surveys of plants.

In the list of the ST plants of [18], here reproduced as Table 1, there are only 34 CSP ST plants worldwide. Only 3 above 20 MW of capacity are operational, ISEGS of 377 MW capacity since 2014, Crescent Dunes Solar Energy Project (Tonopah) of 110 MW capacity since 2015, and Khi Solar One of 50 MW capacity since 2016. The 377 MW ISEGS plant only producing 703,039 MWh/year (2016), the output of a medium to small scale CCGT plant, has the best data set covering 3 years.

Without a proper, extensive real-world experience, costs, reliability and production data over the plant life span may only be poorly addressed.

\subsection{Parabolic trough typical design parameters}

The most common CSP systems are PT. A PT is made up of a linear parabolic reflector concentrating the sun light onto a tubular receiver. The receiver is located along the focal line of the reflector. The tubular receiver is filled with a working fluid. The RF may be oil, MS or water/steam. The reflectors follow the sun with tracking along a single axis. The working fluid is heated as it flows through the receiver up to temperatures from 390 to $500{ }^{\circ} \mathrm{C}$, depending on the fluid used. If oil or MS, this fluid is then used as the heat driving the production of steam for the power cycle in a heat exchanger. The shaped mirrors of a PT focus the sun light on a tube running along the focus line with an 80 times concentration. The sun light is absorbed by tube that is often in a glass vacuum, and delivered to the RF.

PT are in principle less efficient than ST [19], as the temperature of the hot source is typically larger in ST installations, and the efficiency of a Carnot machine is well known to change with the temperature of hot and cold sources as

$$
\eta=1-\frac{T_{C}}{T_{H}}
$$

where $\mathrm{T}_{H}$ is the temperature of the hot source and $\mathrm{T}_{C}$ is the temperature of the cold source. They are however much 
Table 1: List of solar power tower projects (from [18]).

\begin{tabular}{|c|c|c|c|}
\hline Project & $\begin{array}{c}\text { capacity } \\
\text { MW }\end{array}$ & status & year start \\
\hline Tamarugal Solar Energy Project & 450 & under development & \\
\hline Likana Solar Energy Project & 390 & under development & \\
\hline Ivanpah Solar Electric Generating System (ISEGS) & 377 & operational & 2014 \\
\hline Copiapó & 260 & under development & \\
\hline Golmud & 200 & under construction & \\
\hline Aurora Solar Energy Project & 135 & under development & \\
\hline 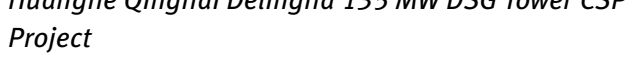 & 135 & under development & \\
\hline NOOR III & 134 & under construction & \\
\hline Ashalim Plot B (Megalim) & 121 & under construction & \\
\hline Atacama-1 & 110 & under construction & \\
\hline Crescent Dunes Solar Energy Project (Tonopah) & 110 & operational & 2015 \\
\hline Golden Tower 100MW Molten Salt project & 100 & under development & \\
\hline Redstone Solar Thermal Power Plant & 100 & under development & \\
\hline SunCan Dunhuang 100 MW Phase II & 100 & under construction & \\
\hline Yumen 100MW Molten Salt Tower CSP project & 100 & under development & \\
\hline MINOS & 52 & under development & \\
\hline Hami 50 MW CSP Project & 50 & under development & \\
\hline Khi Solar One & 50 & operational & 2016 \\
\hline Qinghai Gonghe 50 MW CSP Plant & 50 & under development & \\
\hline Shangyi 50MW DSG Tower CSP project & 50 & under development & \\
\hline Supcon Solar Project & 50 & under construction & \\
\hline Yumen 50MW Molten Salt Tower CSP project & 50 & under construction & \\
\hline Planta Solar 20 (PS20) & 20 & operational & 2009 \\
\hline Gemasolar Thermosolar Plant (Gemasolar) & 19.9 & operational & 2011 \\
\hline Planta Solar 10 (PS10) & 11 & operational & 2007 \\
\hline SunCan Dunhuang 10 MW Phase I & 10 & operational & 2016 \\
\hline Sierra SunTower (Sierra) & 5 & operational & 2009 \\
\hline Lake Cargelligo & 3 & operational & 2011 \\
\hline ACME Solar Tower & 2.5 & operational & 2011 \\
\hline Jülich Solar Tower & 1.5 & operational & 2008 \\
\hline Sundrop CSP Project & 1.5 & operational & 2016 \\
\hline Jemalong Solar Thermal Station & 1.1 & operational & 2016 \\
\hline Dahan Power Plant & 1 & operational & 2012 \\
\hline Greenway CSP Mersin Tower Plant & 1 & operational & 2012 \\
\hline
\end{tabular}

simpler and they are less expensive to build and operate. Hence, the much wider use [6].

Reference PT specifications change with the RF and the availability of TES (data from [8, 19-23]):

- $\quad$ For oil as the RF, the receiver temperature is $390{ }^{\circ} \mathrm{C}$, the peak flux on receiver is about $25 \mathrm{~kW} / \mathrm{m}^{2}$, the hot storage temperature is $390^{\circ} \mathrm{C}$, the cold storage temperature is $290{ }^{\circ} \mathrm{C}$, and the condenser temperature for heat rejection is $40{ }^{\circ} \mathrm{C}$.

- $\quad$ For MS (nitrate salt) as the RF, the receiver temperature is $500{ }^{\circ} \mathrm{C}$, the peak flux on receiver is about $25 \mathrm{~kW} / \mathrm{m}^{2}$, the hot storage temperature is $500^{\circ} \mathrm{C}$, and the cold storage temperature is $300{ }^{\circ} \mathrm{C}$.

- In case of water/steam as the RF, the receiver temperature is $500{ }^{\circ} \mathrm{C}$, the peak flux on receiver is about
$25 \mathrm{~kW} / \mathrm{m}^{2}$. There are in this case no hot and cold storage tanks.

\subsection{Solar tower typical design parameters}

A ST concentrates the sun light from a field of heliostats on a central tower. The heliostats are dual axis tracking reflectors grouped in arrays. They concentrate sunlight on a relatively small central receiver located at the top of the tower. The sun light with ST is much more concentrated than in PT. The RF may be heated to temperatures from 500 to $1000{ }^{\circ} \mathrm{C}$ depending on the RFs and the solar concentration design. When MS is used, it serves as the heat driving the production of steam for the power cycle in a heat exchanger. When water/steam is used, then there is no need 
of this heat exchanger. The field of heliostats focus the light on top of the tower with a 500 to 1000 times concentration. Light is absorbed by metal tubes and delivered to the RF, either water/steam or MS (nitrate salt). Due to sunlight shaded, blocked, absorbed, or spilled, there is a $40 \%$ loss of incident light collected by the RF. Receiver, piping, and tank thermal losses further reduced the amount of energy transferred to the power cycle.

The reference ST specifications change with the RF and the availability of TES (data from [8, 20, 24, 25]):

- $\quad$ For MS (nitrate salt) as the RF, the receiver temperature is $565{ }^{\circ} \mathrm{C}$, the peak flux on receiver is $1,000 \mathrm{~kW} / \mathrm{m}^{2}$, the hot storage temperature is $565^{\circ} \mathrm{C}$, the cold storage temperature is $290^{\circ} \mathrm{C}$, and the condenser temperature for heat rejection is $40^{\circ} \mathrm{C}$.

- In case of water/steam as the RF, the receiver temperature is $550{ }^{\circ} \mathrm{C}$, the peak flux on receiver is $>300 \mathrm{~kW} / \mathrm{m}^{2}$. The hot and cold storage tanks are not available in this case.

\subsection{Additional information of existing plants from thermal models}

Computational tools are used for heat balance design of thermal power systems, and for simulation of off-design plant performance. Hence, thermal models are the best avenue to appreciate design variants in CSP ST plants from the point of view of electricity output.

A scheme of the Rice CSP ST facility is provided in Figure 1 (from [26]). The Rice Solar Energy Project was a latest generation CSP ST project [27] put on hold. The proposed location was Rice, California (Mojave Desert, near Blythe). The gross turbine capacity is $150 \mathrm{MW}$. The land area is $5.706 \mathrm{~km}^{2}$. The solar resource is $2,598 \mathrm{kWh} / \mathrm{m}^{2} /$ year. The planned electricity generation was $450,000 \mathrm{MWh} /$ year. The heliostat solar-field aperture area is $1,071,361 \mathrm{~m}^{2}$. The number of heliostats is 17,170, and every heliostat has an aperture area of $62.4 \mathrm{~m}^{2}$. The tower height is $164.6 \mathrm{~m}$. The receiver type is external, cylindrical. The heat-transfer fluid is MS. The receiver inlet temperature is $282{ }^{\circ} \mathrm{C}$, and the receiver outlet temperature is $566^{\circ} \mathrm{C}$. The steam Rankine power cycle has a maximum pressure of 115 bar. The cooling method is dry cooling. The TES is achieved by raising MS temperature from $282{ }^{\circ} \mathrm{C}$ to $566{ }^{\circ} \mathrm{C}$. The TES efficiency is $99 \%$.

A scheme of the ISEGS ST facility discussed here after (as well as schemes of PT installations such as the Kramer Junction PT facility) is also provided in [26] and [8]. The reader is referred to these models for the further detailed information eventually needed to complement the information here provided. The power cycle is a relatively simple Rankine cycle of limited efficiency mostly due to the Carnot law.

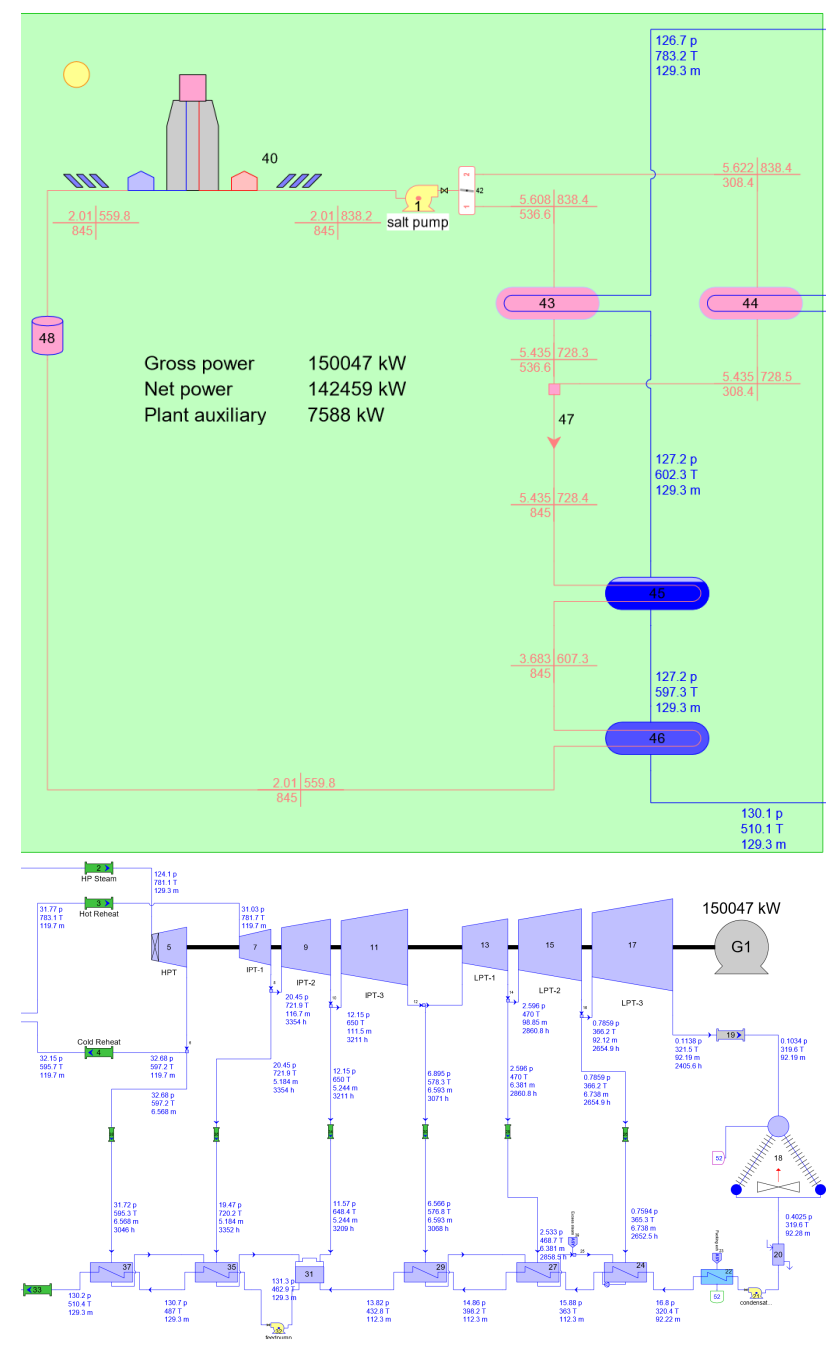

Fig. 1: Thermoflow scheme of the design point balance for the Rice concentrating ST facility. Courtesy of Thermoflow, www.thermoflow. com. All data extracted from public available sources, California Energy Commission.

\subsection{Operational parameters}

Plant level data of electricity production and NG consumption of CSP plants in the United States are provided in [28]. Data of [28] includes the energy input from both the sun and the NG. Reference design data are provided in [27]. 
Capacity factors of CPS plants with and without NG boost such as ISEGS (Jan-2014 start, ST, no TES), SEGS (various starting dates, Oct-1990 SEGS-IX, PT, no TES) and Solana (Dec-2013 starting date, PT, TES) have been discussed and compared in [8].

The capacity factor $\epsilon_{1}$ is defined as the ratio of the actual electricity produced in a year $\mathrm{E}$ [MWh] with the product of net capacity $\mathrm{P}[\mathrm{MW}]$ by number of hours in a year:

$$
\epsilon_{1}=\frac{E}{P \cdot 8760}
$$

This capacity factor does not account for the consumption of NG.

Ref. [8] suggests as a first option to account for the NG consumption by multiplying the above capacity factor by the ratio of the solar energy input $\mathrm{Q}_{\text {Sun }}$ to the total solar energy and $N G$ energy input $Q_{S u n}+Q_{N G}$, all in [MWh]:

$$
\epsilon_{2}=\frac{E}{P \cdot 8760} \cdot \frac{Q_{\text {Sun }}}{Q_{\text {Sun }}+Q_{N G}}
$$

Ref. [8] suggests two other way to evaluate the net capacity factors.

A third capacity factor $\epsilon_{3}$ is defined as the ratio of the actual electricity produced reduced of the electricity produced by burning the NG in a gas turbine (GT) plant with efficiency $\eta_{G T}=30 \%$, with the product of net capacity by number of hours in a year:

$$
\epsilon_{3}=\frac{E-Q_{N G} \cdot \eta_{G T}}{P \cdot 8760}
$$

A fourth capacity factor $\epsilon_{4}$ is finally defined as the ratio of the actual electricity produced reduced of the electricity produced by burning the NG in a CCGT plant with efficiency $\eta_{C C G T}=60 \%$, with the product of net capacity by number of hours in a year:

$$
\epsilon_{4}=\frac{E-Q_{N G} \cdot \eta_{C C G T}}{P \cdot 8760}
$$

An important parameter not accounted for is the requested electricity generation profile. Without TES, the costs per installed capacity are lower, because there is cost associate to the TES and because the turbine is oversized compared to the solar field. However, the electricity production is strongly linked to the sun availability. More than a simple comparison between capacity factors, it is important to compare planned and actual capacity factors to understand the maturity of the technology.

\subsection{Prior analyses of operational data}

The capacity factors of the three largest CSP projects,
- $\quad$ ISEGS (ST, no TES, NG boost),

- $\quad$ SEGS (PT, no TES, NG boost)

- $\quad$ and Solana (PT, TES, no NG boost),

were analyzed in Ref. [8]. Results are summarized below:

- $\quad$ Over the period July 2016 to June 2017 (latest 12 months), without accounting for the NG consumption, $\epsilon_{1}$ were $22.98 \%, 21.59 \%$ and $23.67 \%$ for ISEGS $1-2-3,22.54 \%$ for SEGS IX and $32.65 \%$ for Solana.

- By accounting for the consumption of the $\mathrm{NG}$ at the actual energy conversion efficiency $\eta$ of the plant, $\epsilon_{2}$ are smaller for ISEGS $1-2-3$ at $19.20 \%, 18.04 \%$ and $20.12 \%$ and for SEGS IX at $19.91 \%$, while obviously $\epsilon_{2}=\epsilon_{1}$ for Solana.

- By considering the energy conversion efficiency of a reference GT plant $\eta=30 \%$, the $\epsilon_{3}$ are marginally better in ISEGS 1-2-3 and SEGS IX, while $\epsilon_{3=} \epsilon_{1}$ for Solana.

- Finally, by accounting for the consumption of the $\mathrm{NG}$ at the energy conversion efficiency of a reference CCGT plant $\eta=60 \%, \epsilon_{4}$ are much smaller for ISEGS 1$2-3$ at $15.83 \%, 14.80 \%$ and $17.07 \%$, and much smaller for SEGS IX at $17.91 \%$, while $\epsilon_{4}=\epsilon_{1}$ for Solana.

This analysis confirms the well-established fact [2934] that TES plays a significant role in producing much higher capacity factors in present installations, as by TES the power available to the turbine is extended but it is also reduced.

\subsection{A critique to the boost by natural gas}

The above analysis shows as the use of NG to boost the electricity production in a CSP plant is not motivated, being the fuel energy used at a much lower efficiency than in a CCGT plant, and everything but cost effective. While the hybridization with fossil fuels may be motivated by policies pushing renewable energy production rather than the reduction of fossil fuel usage, the actual benefits in terms of pollution reduction and affordability of energy are quite questionable [8]. Also considering all the issues of integrating intermittent, variable renewable energy electricity into the grid [35-37], there is no point for a better environment and a better economy of fostering hybridization of CSP with fossil fuel plants as the simple upgrade of traditional plants burning fossil fuels possibly including much cheaper solar ponds costs less while also reducing fossil fuel consumption.

CCGT plants can work with an efficiency as high as $62.21 \%$ (the 605 MW Bouchain power plant $[38,39]$ ) with- 
out any of the constraints of the renewable energy plants. The Bouchain power plant replaces a prior coal plant on $25 \%$ of the footprint of the old plant. It is generating more power with $50 \%$ less $\mathrm{CO}_{2}$ emission.

CCGT plants do not have the constraints of the operation of renewable energy plants such as solar plants. These plants have theoretically the opportunity to operate $24 / 7$ all the year round except than the periods of the scheduled maintenance. Their capacity factors can exceed $90 \%$ if contributing to the base-load, or at a lesser extent to match the spikes in the load demand or to supplement the intermittent renewable energy supply. In 2015, the CCGT plants of the US have been operated with average capacity factors of $56 \%$ [40].

While many policies dedicated to CSP still consider hybridization to make the overall CSP investment more profitable by increasing the usage of the power plant and saving the costs of TES, CSP should not be coupled to the burning of fossil fuels. In our opinion, CSP ST only makes sense as a standalone technology that does not require any fossil fuel.

\subsection{Analysis of latest costs and production data}

Table 2 provide the latest costs and production data of the most recent CSP ST and PT installations. Opposite to many projections in the literature, costs are here actual, as actual is the production. As there are only 2 CSP ST projects operational worldwide with a significant capacity $>50 \mathrm{MW}$, ISEGS and Crescent Dunes, the first without TES and the second with TES, we also use data of 2 CSP PT projects with and without TES, Solana and SEGS, to make a minimal statistic based on facts.

The ISEGS CSP ST plant had a cost (2014 values) of 2,200 $\mathrm{m} \$$ for $377 \mathrm{MW}$ of capacity, or 5,9836 $\$ / \mathrm{kW}$. In terms of 2017 values (US inflation calculator [101]) this corresponds to 2,294 $\mathrm{m} \$$ and $6,084 \$ / \mathrm{kW}$. The plant has no TES. The heliostat solar-field has an aperture area of $2,600,00 \mathrm{~m}^{2}$, the heat-transfer fluid is water/steam, the receiver inlet temperature is $249^{\circ} \mathrm{C}$, the receiver outlet temperature is $565{ }^{\circ} \mathrm{C}$. The Rankine power cycle max pressure is 160 bar. The latest production data of ISEGS $[8,12-$ 14], [15] indicates capacity factors of not more than 22$23 \%$ despite burning substantial amounts of NG translating in significant additional generating costs and pollution, with the actual capacity factor drastically reducing of more than one third to less than $15 \%$ once the consumption of NG is properly accounted for at the fuel energy conversion efficiency of a reference CCGT. The ISEGS power plant was approved in 2014 to burn up to 525 million cubic feet of NG per year [41] and in 2014, the plant emitted 46,084 metric tons of $\mathrm{CO}_{2}$ by burning NG, that is twice the pollution threshold at which power plants and factories in California are required to participate in the state's cap and trade program [42]. While the planned electricity generation was an optimistic 1,079,232 $\mathrm{MWh}$ /year [12], or an annual solar-to-electricity efficiency of $28.72 \%$, the actual data [13-15] for the year 2014, 2015 and 2016 indicate an actual production of 419,085, 653,122 and 703,039 MWh/year despite the huge consumption of NG 774,525, 1,245,986 and 1,290,308 MMBtu to boost production. NG consumption of two months of 2014 is missing.

The SEGS installation comprises 8 different plants presently operational, built over a time span of several years. It consists of SEGS II located at Daggett, SEGS IIIVII located at Kramer Junction and SEGS VIII-IX located at Harper Lake. SEGS I located at Daggett is not operational any more. SEGS X had been in construction but it was never finished. SEGS XI and SEGS XII were planned but never built. The 80 MW SEGS IX has Terminol as receiver fluid, and a temperature at the exit of the $483,960 \mathrm{~m}^{2}$ solar field of $390{ }^{\circ} \mathrm{C}$. The Rankine power cycle max pressure is 100 bar. [43] claims that a plant like the 30 MW SEGS VI plant in Kramer Junction could have had in 2002 cost of $3,204 \$ / \mathrm{kW}$. This translates in an optimistic specific cost of 4,398 \$/kW 2017 values. [105] claims a capital cost of $99.3 \mathrm{~m} \$ 1989$ values for the specific plant, or 3,310 \$/kW, translating in a much larger 2017 cost of $6,584 \$ / \mathrm{kW}$. As the costs for SEGS based on projections and not actual costs are non-accurate, these values are not included in Table 2.

Production data and NG consumption of the SEGS facility is estimated from the latest SEGS IX plant data, the more recent and best performing. The plant has no TES. The capacity factors of SEGS IX are not far from the values of ISEGS, despite SEGS IX started operation almost 25 years before ISEGS.

The cost of Solana (PT, TES) is approximately $2,000 \mathrm{~m} \$, 10 \%$ less than the ISEGS ST facility that was completed only two months later, however for 34\% less net capacity [8]. The plant has TES. Solana has a specific cost of $8,258 \$ / \mathrm{kW} 2017$ values. The production data of Solana is much better than SEGS and ISEGS, with latest capacity factors of about $33 \%$, even if smaller than the planned $43.1 \%$. Solana is by far the best performing large CSP plant in the United States. The solar-field aperture area is 2,200,000 $\mathrm{m}^{2}$, the heat-transfer fluid is Therminol VP-1 - Xceltherm MK1. The solar-field Inlet Temperature is $293{ }^{\circ} \mathrm{C}$, the solar-field outlet Temperature is $393{ }^{\circ} \mathrm{C}$. 6 hours TES is obtained by using MS with two tanks. The Rankine power cycle max pressure is 100 bar. 
The 110 MW Crescent Dunes Solar Energy Project [44, 45], the only other project of reasonable size in the world featuring the CSP ST technology and currently operational, had a cost of $975 \mathrm{~m} \$ 2015$ values, corresponding to $1,015 \mathrm{~m} \$$ of 2017. This corresponds to 8,864 \$/kW 2015 values or 9,227 \$/kW 2017 values. The heliostat solar-field has an aperture area of 1,197,148 $\mathrm{m}^{2}$, the heat-transfer fluid is MS, the receiver inlet temperature is $288{ }^{\circ} \mathrm{C}$, the receiver outlet temperature is $565^{\circ} \mathrm{C}$. The plant has TES and no boost by NG. The TES has 2-tanks, storage capacity 10 hours, TES achieved by raising salt, temperature from 288 to $565^{\circ} \mathrm{C}$. The Rankine power cycle max pressure is $110 \mathrm{bar}$.

The project started operation in November 2015. While the planned electricity generation was $500,000 \mathrm{MWh} /$ year (capacity factor $51.89 \%$ ), the actual electricity produced in 2016 was only $127,308 \mathrm{MWh} /$ year. During the year 2016, the plant was operated 10 months January to October. The plant has been so far out of service for about one half of the lifetime, from November 2015 to July 2017. Crescent Dune was indeed shut-down in October 2016 due to a leak in a MS tank and it returned to operation only in July 2017. By using the actual production of 2016, the capacity factor is only $13 \%$.

From Table 2 we may conclude that PT may possibly permit lower costs than ST, while TES significantly add to the cost of the plant, but apart from reliability issues, it also improves the electricity production.

According to the latest construction cost data for electric generators installed in 2015 by the US Energy Information Administration [46], capacity weighted costs in $\$ / \mathrm{kW}$ were 1,661 \$/kW for wind, $696 \$ / \mathrm{kW}$ for NG, 2,921 \$/kW for solar photovoltaic. According to the latest (2017) outlook of cost and performance characteristics of new generating technologies by the US Energy Information Administration [47], solar thermal is about 3,908 $\$ / \mathrm{kW}$, solar photovoltaic 2,169 \$/kW, wind 1,576 \$/kW, wind offshore 4,648 $\$ / \mathrm{kW}$, conventional combustion turbine is $1,040 \$ / \mathrm{kW}$, advanced combustion turbine is $640 \$ / \mathrm{kW}$. We may also conclude from Table 2 that the values of [47] are optimistic, i.e. the actual costs differ considerably from the estimates of expert panels. While Table 8 - Cost and performance characteristics of new central station electricity generating technologies of [47] reports a base overnight cost in $2016(2016 \$ / \mathrm{kW})$ of 3,908 for solar thermal, ISEGS, Solana and Crescent Dunes have 2017 costs of 6,085, 8,258 and 9,227 \$/kW.

It must be mentioned that the capacity weighted cost is a measure largely in favor of renewable energy plants, typically delivering much smaller capacity factors than fossil fuel plants. The actual costs of CSP per installed capacity of ISEGS, SEGS, Solana and Crescent Dunes are gen- erally high, and much larger than the planned values. Additionally, the actual production of electricity of ISEGS, SEGS, Solana and Crescent Dunes has been much less than the planned values, and by far much smaller than the values potentially achievable in CCGT plants [8]. In the cases of ISEGS and SEGS, the NG consumption has further impacted on the economy and the emissions [8], even if surprisingly this consumption is not properly accounted for. Opposite to SEGS, the costs of ISEGS and Solana, that started production almost simultaneously, are accurate, similarly to Crescent Dunes, that started production only one year later.

Maintenance or rectification costs are unknown and hence not included in the table.

Data for ISEGS are from [12-15], data for Solana are from [48, 49], data for Crescent Dunes are from [44, 45], and data for SEGS IX are from $[50,51]$ as per the retrieved date.

\subsection{Discussion of the costs and production data analysis}

It may be argued that the above analysis is based on a small population. This is unfortunately the best possible data base if we want to rely on plants built and operational. As it is not uncommon that ambitions renewable energy projects especially CSP are never completed (Rice was put on indefinite hold in 2014 for financial issues, while SEGS $\mathrm{X}$ was just started, and SEGS XI and XII were only planned, when their developer filed for bankruptcy in 1992), we prefer to discuss the state of the art of a technology based on actual data of costs and electricity production and not on expectations that may prove to be wrong.

The latest list of CSP projects worldwide published by the National Renewable Energy Laboratory [27] includes 184 projects. However, 10 projects are currently non-operational, and 78 are under construction, contract or development. Of the 96 operational, only 7 have net capacity more than $100 \mathrm{MW}$ and only 4 have net capacity more than $150 \mathrm{MW}$. Discussing the CSP contribution to the global energy mix, it does not make any sense to consider small size plants. CSP plants of capacity not exceeding $150 \mathrm{MW}$, with capacity factors of the order of 0.2 , translate in annual power outputs not exceeding $262.8 \mathrm{GWh}$, that is not certainly indication of an important contribution.

All the 4 plants of net capacity exceeding $150 \mathrm{MW}$ are in the United States. These are the 377 MW Ivanpah Solar Electric Generating System (ISEGS) and the $250 \mathrm{MW}$ each Solana Generating Station mentioned in the above analysis, plus Genesis Solar Energy Project and Mojave So- 
Table 2: Actual costs and performances of the ISEGS, SEGS, Solana and Crescent Dunes plants. Notes: ${ }^{(1)}$ SEGS IX only. ${ }^{(2)}$ January to October 2016.

\begin{tabular}{|c|c|c|c|c|}
\hline Project & ISEGS 1-3 & SEGS II-IX & SOLANA & $\begin{array}{l}\text { Crescent } \\
\text { Dunes }\end{array}$ \\
\hline Type & ST & PT & PT & ST \\
\hline TES & no & no & yes & yes \\
\hline NG combustion & yes & yes & no & no \\
\hline year start & Jan-14 & Oct-90 $(1)$ & Dec-13 & Oct-15 \\
\hline capacity MW & 377 & 340 & 250 & 110 \\
\hline planned solar electricity generation MWh/year & 1079232 & NA & 944000 & 500000 \\
\hline planned solar capacity factor & $32.68 \%$ & NA & $43.11 \%$ & $51.89 \%$ \\
\hline $\begin{array}{l}\text { latest } 12 \text { months capacity factor not } \\
\text { accounting for the } N G \text { consumption }\end{array}$ & $22.75 \%$ & $22.54 \%(1)$ & $32.65 \%$ & $13.21 \%{ }^{(2)}$ \\
\hline $\begin{array}{l}\text { latest } 12 \text { months capacity factor accounting for } \\
\text { the NG consumption } \eta=60 \%\end{array}$ & $15.90 \%$ & $17.91 \%$ & $32.65 \%$ & $13.21 \%^{(2)}$ \\
\hline 2017 reference cost $m \$$ & 2294 & NA & 2065 & 1015 \\
\hline 2017 specific cost $\$ / k W$ & 6085 & NA & 8258 & 9227 \\
\hline
\end{tabular}

lar Project. Genesis and Mojave Solar Project are parabolic trough but no thermal energy storage. The $7^{\text {th }}$ largest CSP plant in the world, the 110 MW Crescent Dunes Solar Energy Project, is also in the United States. We also included Crescent Dunes in our analysis. The $5^{\text {th }}$ and $6^{\text {th }}$ plants are not in the United States. The 146 MW Noor I is in Morocco, and the 125 MW Dhursar is in India. While Noor I is parabolic trough, Dhursar is Fresnel. For Noor I, we do not have same data of actual costs and electricity production we have mined for the United States plants. ISEGS started production January 2014, Solana October 2013. Genesis March 2014, Mojave Solar Project December 2014 and Crescent Dunes November 2015. Hence, all of them are very recent. This is the state of the art of the technology.

The SEGS plants are also included in the analysis. The total $354 \mathrm{MW}$ of installed capacity unfortunately came from 8 different individual plants. By considering the two largest 80 MW plants in Harper Lake a single installation (as it is done for the 3 installations of Ivanpah), we match the requirement of more than $150 \mathrm{MW}$ of power. As SEGS has been built in the 1980s, this latter plant gives an idea how much we have progressed over the last three decades.

The latest (2016) actual electricity production of ISEGS; Solana; Genesis; Mojave Solar Project; Crescent Dunes and SEGS IX are analyzed in [106]. From their net capacities, the actual capacity factors are $21.29 \%$; $29.39 \%$; $28.50 \% ; 28.53 \% ; 13.21 \%$ and $22.54 \%$. The planned capacity factors are conversely $32.68 \% ; 43.11 \% ; 26.48 \% ; 27.40 \%$ and $51.89 \%$ while this parameter is not available for SEGS IX. In case of Ivanpah and in lesser extent SEGS IX, the capacity factors drastically reduce by accounting for the natural gas combustion. The result of the further expanded data base of [106] confirm the results of Table 2. The more consolidated parabolic trough technology without any molten salt thermal energy storage of Genesis and Mojave Solar Project appears to be superior to the most sophisticated solutions still suffering of the lack of maturity and reliability such as Ivanpah and Crescent Dunes and in a minor extent Solana.

\section{Survey of development trends in CSP ST technology}

In Section 2 we provided the actual data of power plants currently operational, including energy outputs and costs of ISEGS (ST), SEGS (PT), Solana (PT, MS TES) and Crescent Dunes (ST, MS TES). ISEGS and Crescent Dunes are the state-of-the-art of the operational CSP ST technology. Based on the real-world experience, the outlook of the CSP ST technology is less brilliant than expected by projections. Hence, there is an urgent need to further progress the technology rather than promoting production of substandard plants. Here we survey the developments being sought to improve the current CSP ST technology, with the advertence that the discrepancies in between actual and projected costs and production data make the claims of the literature speculative. Goal of the survey is only to list the most promising development trends.

On the bright side, as explained in [52, 53], what is called the "learning rate", i.e. the cost reduction following the expansion of a technology, may give hope. The short-term survival of CSP depends on accelerated expansion and sufficient cost decrease. Ref. [52] identified the learning rate of CSP and found that it exceeded $20 \%$ in the last 5 years. Each time the global CSP capacity doubled, investment costs decreased by over $20 \%$. While this fig- 
ure may be optimistic, as it is larger than prior estimates such as [102-104], and it is still based on a very scattered and incomplete data base, for sure there is a learning rate. Ref. [52] found the learning rate to be highly volatile, reflecting the start-stop pattern of the expansion of CSP experienced so far. Hence, continuity in the R\&D effort as well as in the development of an industrial product may ultimately deliver the sought benefits from CSP. Latest cost reductions mentioned in [53] are certainly an indication of the benefits of expanding the CSP ST technology knowhow.

Design, construction and operating technical and economic issues are considered in the literature to various extents. CSP ST have many variants for receivers, working fluids, power cycles, type, number and layout of heliostats, height of tower, condenser, turbine, heat exchangers and TES. As an example of a preliminary introductory survey, Ref. [54] examines some of the main parameters of existing plants, solar energy to electricity conversion efficiency, and mirror and land area per $\mathrm{MW}_{e}$ of capacity, packing density, configuration of the field layout, receiver size, tower height and cost of the plant.

\subsection{Energy storage and heat transfer fluid}

Here we report on the improvement being sought by using a TES with different options for the receiver and the TES fluids. This is the main area of development being considered, as the added value of CSP compared to other renewables is the ability to produce electricity potentially $24 / 7$ through TES.

TES is the key to achieve high capacity factors and avoid NG boost. TES allows improved dispatch-ability (generation on demand) of power from a CSP plant [19]. TES drastically increases the annual capacity factor [8]. The MS TES technology is the best avenue to generate nonintermittent electricity with CSP and achieve capacity factors above 0.3 , and potentially up to 0.4 . A 10 hour TES eliminates the need for a NG back up or boost of electricity production at sunrise and in the evening peak hours [8].

Next generation CSP plants will very likely consist of four major units, solar field to concentrate the sun light energy, ST MS receiver to convert the solar energy into thermal energy, TES section to store the thermal energy using the MS, and finally power block generating electricity through a steam turbine. While the cost will further increase because of the TES, it will be paid back by the increased production and dispatch-ability.

The current best RF and TES fluid is MS that, however, has the drawback of having low degradation temper- ature and high melting temperature, in addition to other downfalls such as corrosion and heat tracing. Solar salt, $60 \% \mathrm{NaNO}_{3}$ and $40 \% \mathrm{KNO}_{3}$, is used as a low-cost $\mathrm{RF}$ and TES fluid. MS temperatures typically go up to $565^{\circ} \mathrm{C}$. This permits superheated steam generation. MS has good heat transfer characteristics [55]. As major downfalls, the salt is freezing below $220^{\circ} \mathrm{C}$, heat tracing is required, and draining of receiver and other system components during the night must be provided. Furthermore, the salt may degrade at temperatures higher than $600{ }^{\circ} \mathrm{C}$ and depending on salt quality it can generate corrosion of metallic components [55].

Alternative fluids are therefore under investigation for a broader range of operation and for cost and performance advantages, as RF and/or the TES fluid. The power block fluid is usually water/steam, but other fluids are also considered for the power block, as it is discussed in another paragraph. There is obviously the opportunity to use a single fluid as receiver, TES and power block fluid. Water/steam is the most obvious example.

Ref. [56] reviewed various types of RF including air, water/steam, thermal oils, organic fluids, molten-salts and liquid metals. The different alternatives were compared with reference melting temperature, thermal stability and corrosion with stainless steels and nickel based alloys the piping and container materials. MS shows advantages operating up to $800{ }^{\circ} \mathrm{C}$.

Different alternatives for the RF are mentioned in [55]. The presentation includes alternative RF as well as receiver technologies. MS, water/steam, air in open/closed systems, liquid metals, solid particles and other gases are considered as heat transfer medium. Classification is by maturity of technologies. It includes MS and water/steam as state of the art technology, open volumetric air receiver as "first-of-its-kind" technology, then pressurized air receivers as technology in pilot phase, liquid metals and solid particles as technology under development. The different receiver technologies proposed in [55] are reviewed in a subsequent specific paragraph.

The impact of the fluid in a flat plate, high temperature, TES unit with flat slabs of phase change materials is studied in [57]. Six gaseous and liquid fluids are compared. For the capacity rate considered, liquid sodium was the best performing ( $99.4 \%$ of the ideal electricity to grid). Solar salt achieved a 93.6\% performance. Atmospheric air, air at 10 bars, s- $\mathrm{CO}_{2}$ at 100 bar and steam at 10 bar achieved performances between $87.9 \%$ and $91.3 \%$. The work concludes that gases are comparable to liquids as TES fluids for the specific application and it mentions that gases may also be used as the working fluid in the power block. 
CSP TES systems are also reviewed in [58]. Various aspects are discussed including trend of development, different technologies of TES systems for high temperature applications $\left(200-1000^{\circ} \mathrm{C}\right)$ with a focus on thermochemical heat storage, and storage concepts for their integration in CSP plants. TES systems are considered a necessary option for more than $70 \%$ of the new CSP plants being developed. Sensible heat storage technology is the most used TES in CSP plants in operation, for their reliability, low cost, easy to implementation and large experimental feedback. Latent and thermochemical energy storage (TCES) technologies have much higher energy density. This gives them better perspectives for future developments. TCES are specifically covered in a following paragraph. New concepts for TES integration include coupled technology for higher operating temperature and cascade TES of modularized storage units for intelligent temperature control.

The current commercial TES systems used in CSP plants either steam accumulators or MS are reviewed in [59]. The economic value of the TES system is assessed by the calculation of the LCOE, an economic performance metric, of the TES itself rather than the full plant. Calculations were done for different plant configurations and storage sizes varying from 1 to $9 \mathrm{~h}$ of operation at full capacity. LCOE is shown to be a valid argument for the selection of the TES, even if other aspects not included also play a relevant role.

The opportunity to adopt particle suspensions as RF, TES fluid, and power block fluid is considered in [60]. Values of the heat transfer coefficient up to $1,100 \mathrm{~W} / \mathrm{m}^{2} / \mathrm{K}$ (bare tubes) and 2,200 $\mathrm{W} / \mathrm{m}^{2} / \mathrm{K}$ (finned tubes) were obtained for operation of a pilot plant at low superficial gas velocities of $0.04-0.19 \mathrm{~m} / \mathrm{s}$ limiting heat losses by the exhaust air. Despite additional costs for particle handling and an appropriate boiler, the required overall investment and operating costs are significantly lower than the reference MS system, leading to a reduction in LCOE from approximately $125 € /$ MWh to below $100 € / M W h$.

The developments of the last five years and expected for the near future of the most important components of a CSP ST are water/steam, air or $\mathrm{CO}_{2}$ power cycles; water/steam, MS, liquid metals, particles or chemically reacting fluids and the RF; design of heliostats; design of receivers, volumetric, tubular, solar particle receivers; TES and hybridization are all reviewed in [61]. They conclude that there will certainly be an increased number of CSP ST in the near future, but with a significant hold-back until standardization and experience is gained. Within the next 5 years, plants will use either MS or water/steam as the receiver fluid, but most of them will have MS TES. In a 10 years' time, more plants will be MS with TES. However, ac- cording to [61], "The commercial plant designs in 10 years will look not much different than the commercial plant designs today", which is a not desirable option.

Thermochemical energy storage has been proposed to replace the TES. This opportunity is in a very early stage of development. In addition to the classic TES design with two tanks of a properly selected TES fluid, TCES systems have been also proposed. TCES is the reversible conversion of solar-thermal energy to chemical energy.

The TCES systems are reviewed in [62]. TCES has high energy density and low heat loss over long periods than the MS TES. CSP plants with TCES systems are modelled, and sample computational results are provided for ammonia and methane systems with two gas storage options. The gas storage is identified as the main cost driver. The compressor electricity consumption is identified as the main energy driver.

Ref. [63] reports of a pilot-scale redox-based TCES system. The storage unit is made of inert honeycomb supports (cordierite) coated with $88 \mathrm{~kg}$ of redox active material (cobalt oxide). When crossing respectively the reduction/oxidation temperature of the $\mathrm{Co}_{3} \mathrm{O}_{4} / \mathrm{CoO}$ pair, the heat absorbed or released by the chemical reaction allows to store or release energy at constant temperature. Within the limit of a campaign of 22 thermochemical charge/discharge cycles, there was no measurable cycle-to-cycle degradation. The system average capacity was very close to the ideal case. The TCES system offers a storage capacity of $47.0 \mathrm{kWh}$ vs. the $25.3 \mathrm{kWh}$ of the same volume of a sensible-only storage unit made of uncoated cordierite honeycombs.

\subsection{Power cycles and power cycles fluids}

Here we report on the improvement being sought by using different power cycles and power cycle fluids. This is an area of development receiving significant attention that may possibly produce results within the next decade.

Supercritical steam [64] and supercritical $\mathrm{CO}_{2}$ $\left(\mathrm{sCO}_{2}\right)[65]$ power cycles are being considered to improve the conversion efficiency thermal-electric cycles. Ref. [66] computed the thermodynamic irreversibility such as convective and radiative loss on tower receiver and thermal resistance in heat exchangers. Increasing the receiver working temperature increases both thermal and exergy conversion efficiencies only until an optimum temperature is reached. The optimum temperature increases with the concentration ratio. Increasing the concentration ratio, the conversion efficiency increases only until an optimum concentration ratio is reached. Increasing the 
end reversible engine efficiency increases the thermal conversion efficiency until a maximum value is reached. Then, the conversion efficiency drops dramatically.

The performance of an integrally geared compressorexpander recuperated recompression cycle with $\mathrm{sCO}_{2}$ as the working fluid is modeled in Ref. [67]. Mostly through reduced power block cost and a better cycle model, the LCOE is computed to be $5.98 \not / \mathrm{kWh}$.

Advanced power cycles under consideration for CSP are reviewed in [68]. Supercritical steam turbines are attractive at large scale but presently commercial products are too large for today's CSP ST plants. $\mathrm{SCO}_{2}$ closed loop Brayton cycles are early in their development but promise high efficiency at reasonable temperatures across a range of capacities. In perspective, these cycles may significantly lower the costs. GT combined cycles driven by CSP are one of the highest efficiency options available. Other bottoming and topping cycle configurations are also considered. High temperature component demonstration is indicated as a critical factor.

Three different $\mathrm{SCO}_{2}$ power cycles applied to a high temperature ST CSP system are considered in Ref. [69]. Maximum temperatures are up to $800{ }^{\circ} \mathrm{C}$. The fluid transferring energy from the receiver to the power block is $\mathrm{KCl}-$ $\mathrm{MgCl}_{2}$ MS. The highest efficiency at design conditions is achieved by the Recompression with Main Compression Intercooling (RMCI) configuration with a solar energy to electricity efficiency of $24.5 \%$ and a maximum temperature of $750{ }^{\circ} \mathrm{C}$. The capacity factor is $18.4 \%$. The performance decay from design to average yearly conditions is mostly due to the optical and thermal efficiencies reduction respectively of $-10.8 \%$ and $-16.4 \%$.

Several current $\mathrm{sCO}_{2}$ Brayton cycles for integration into a MS CSP ST system are reviewed in [70]. The intercooling cycle can generally offer the highest efficiency, followed by the partial cooling cycle, and the recompression cycle. The pre-compression cycle can yield higher efficiency than the recompression cycle when the compressor inlet temperature is high. The increase in the hot salt temperature cannot always result in an efficiency improvement. The partial cooling cycle can offer the largest specific work, while the recompression cycle and the split expansion cycle yield the lowest specific work. The MS temperature differences with the simple recuperation cycle, the partial-cooling cycle, and the pre-compression cycle are slightly larger than those with the recompression cycle, the split expansion cycle, and the intercooling cycle. Reheating can decrease the system efficiency in the cases with high hot MS temperature. Larger MS temperature difference may be achieved without reheating than with reheating. While current $\mathrm{sCO}_{2}$ Brayton cycle offer high effi- ciency, challenges for integrating them includes the specific work that is relatively small, and the temperature difference across the solar receiver that is narrow.

More efficient Rankine power cycles are studied in [71]. The temperature and pressure of the main steam and the reheating pressure affect the temperature of the MS in the receiver. If the temperature increases, the receiver efficiency decreases but the power block efficiency increases. If the pressure at the inlet of the turbine increases, the efficiency of the power block increases even more than by increasing the temperature. The reheating pressure is the most influential factor on the plant efficiency. A high reheating pressure decreases the plant efficiency. The best efficiencies were obtained for the supercritical cycle with a low reheating pressure and high temperature. The subcritical cycle at high pressure and temperature performed closely. The investment cost of the different cycles increases with the pressure and the temperature of the power block. Subcritical cycles are less expensive than supercritical cycles even if the cost increase is balanced by the efficiency increase. Subcritical cycles working at $16 \mathrm{MPa}$ and supercritical cycles working with low reheating pressure deliver the same cost per $\mathrm{MW}_{e}$.

Energy and exergy analyses of $\mathrm{sCO}_{2}$ recompression Brayton cycles are proposed in Ref. [72]. The heliostat field layout is optimized for the optical performance on an annual basis. A recompression Brayton cycle uses the heat collected at the receiver. An auxiliary boiler is added prior to the turbine to keep the turbine inlet temperature constant. The net power output is constant $40 \mathrm{MW}$. The highest exergy destruction occurs in the heliostat field. The second highest exergy destruction happens in the boiler's combustion chamber. The combustion exergy destruction rate increases during the winter months when the solar radiation decreases.

The thermal performance of an array of pressurized air solar receiver modules integrated to a GT power cycle for a simple Brayton cycle, a recuperated Brayton cycle, and a combined Brayton-Rankine cycle are studied in [73]. The solar receiver's solar energy to heat efficiency decreases at higher temperatures and pressures. The opposite is true for the power cycle's heat to work efficiency. The optimal operating conditions are achieved with a preheat stage for a solar receiver outlet air temperature of $1300{ }^{\circ} \mathrm{C}$ and an air cycle pressure ratio of 9 , yielding a peak solar energy to electricity efficiency of $39.3 \%$ for the combined cycle.

Alternative cycles' technology certainly needs more work before introduction in full scale CSP ST plants where water/steam Rankine cycles are the best short-term (10 years' time window) solution. According to [61], citing a private communication, only in perhaps 10 years from 
now, there could be a shift to supercritical $\mathrm{CO}_{2}$-based plants.

\subsection{Design of solar field and receiver}

Here we report on the improvement being sought by redesigning solar field and receiver. This is an area of development also receiving significant attention, that may possibly produce significant results within the next decade.

According to Ref. [54], the annual solar energy to electricity conversion efficiency corresponds to an average of about $16 \%$. The packing density has an average of about $20 \%$.

A classification by maturity of receiver technologies is proposed in [55] and has been included in a prior paragraph. In addition to MS and water/steam state of the art technologies, open volumetric air receiver, pressurized air receivers, liquid metals and solid particles are all technologies being developed at different stages of evolution. As the receiver design is not decoupled from the design of the solar field, here we couple together these two aspects.

Gas receivers, liquid receivers, and solid particle receivers are reviewed in [74]. Higher thermal-to-electric efficiencies of $50 \%$ and higher may be achieved by using $\mathrm{sCO}_{2}$ closed-loop Brayton cycles and direct heating of the $\mathrm{CO}_{2}$ in tubular receiver designs, external or cavity, for high fluid pressures of about $20 \mathrm{MPa}$ and temperatures of about $700^{\circ} \mathrm{C}$. Indirect heating of other fluids/materials that can be stored at high temperatures such as advanced MS, liquid metals, or solid particles are also possible, but with additional challenges such as stability, heat loss, and the need for high-temperature heat exchangers.

As per [55], strategies aimed at improving MS systems include higher temperature MS, higher steam parameters, smaller heat exchanger, smaller storage, less critical receiver temperature operation. Means to improve the receiver efficiency include reduction of thermal losses, cavity arrangement, face down can design, standard vacuum absorber for first temperature step, and selective coatings for higher absorption of solar radiation [55]. Optimization of operation includes real time aim point strategy for homogenous receiver temperature, solar pre-heating of receiver, faster start-up and elimination of draining of receiver during clouds [55].

The improvement of the solar flux intercepted by the receiver to increase the peak flux is considered in [75]. They propose a new receiver, named Variable Velocity Receiver (VVR), Figure 2, consisting of a Traditional External Tubular Receiver (TETR) equipped with valves permitting the division of each panel in two independent panels. This in- creases the velocity of the heat transfer fluid in specific zones of the receiver avoiding tube overheating. The novel design also permits better aiming strategies, for an improved optical efficiency of the solar field and a possible reduction of the number of heliostats.

The size of the solar field required by a VVR is $12.5 \%$ smaller than the size required by a traditional TETR. Additionally, the VVR provides advantages for the winter operation when the panels can be split in two, increasing the number of passes and the velocity of the heat transfer fluid.

High temperatures, thermal shocks and temperature gradient from a high, non-homogeneous and variable flux on the receiver walls are responsible for significant stresses. These stresses reduce the life-span of the receiver. Ref. [76] proposes an open loop approach to control the flux density distribution delivered on a CSP ST flat plate receiver. Various distributions of aiming points on the aperture of the receiver are considered. The approach provides interesting indications for the control of the heliostats that may drastically improve the life-span of the component.

The optimization of a solar field layout with heliostats of different size is considered in [77]. Although the use of a single heliostat size is openly questioned in the literature, there are no tools to design fields with heliostats of different sizes in the market. The paper addresses the problem of optimizing the heliostat field layout with two heliostats' sizes.

Ref. [78] numerically studied the influence of wind and return air on a volumetric receiver. Figure 3 presents a sketch of the receiver. The volumetric receiver is a highly porous material which absorbs solar radiation at different depth through its thickness. The effective area for solar absorption is larger than that of thermal radiation losses. A fan draws air through the absorbent pores, and the convective flow captures the heat absorbed. Thanks to the volumetric effect [79], the absorber thermal radiation loss is reduced.

Ref. [80] optically simulated the solar light radiation transmission from the heliostat field to a pressurized volumetric receiver. The optical efficiency of the heliostats' field and the local heat flux distribution within the absorber is computed as a function of time and date, heliostats tracking error and receiver mounting height. The heat flux distribution within the absorber is non-uniform. The maximum heat flux density at the top area is up to $2.58 \cdot 10^{9} \mathrm{~W} / \mathrm{m}^{3}$. The pattern of field efficiency and maximum heat flux density of the absorber resembles those of the solar altitude angle during a day/year. The annual mean field efficiency and the maximum heat flux of the absorber decrease as the tracking error increases. As the re- 

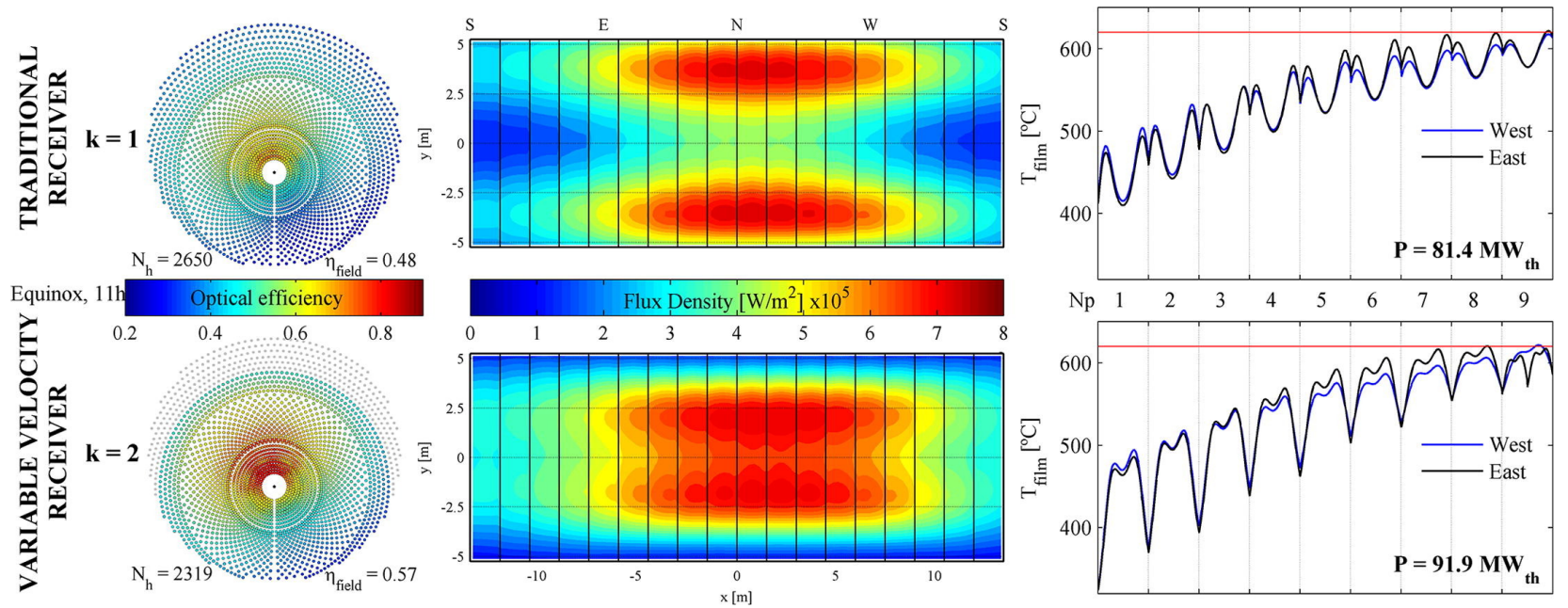

Fig. 2: Operation of the novel Variable Velocity Receiver proposed in [75] vs. a Traditional External Tubular Receiver. Reprinted from Applied Thermal Engineering, Vol. 128, M.R. Rodríguez-Sánchez, A. Sánchez-González, D. Santana, Feasibility study of a new concept of solar external receiver: Variable velocity receiver, Pages No. 335-344, Copyright (2018), with permission from Elsevier.

ceiver mounting height increases, both these parameters are marginally increasing.

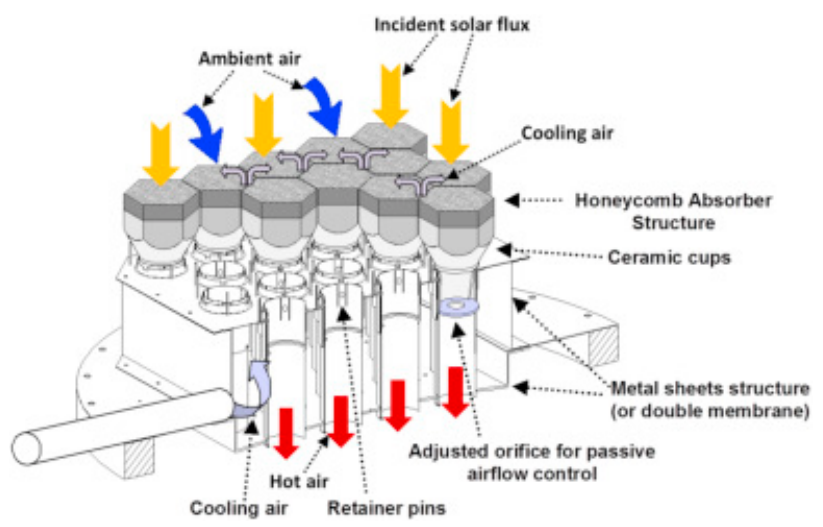

Fig. 3: Volumetric receiver used in [78]. Reprinted from Energy, Vol. 94, Roldán, M.I., Fernández-Reche, J. and Ballestrín, J., Computational fluid dynamics evaluation of the operating conditions for a volumetric receiver installed in a solar tower, Pages No. 844-856, Copyright (2016), with permission from Elsevier.

A dual-receiver with a surrounding solar field is proposed in [81], Figure 4. The design couples an external boiling receiver and a cavity superheating receiver. The design provides a simple yet controllable heat flux distribution on both sections. The dual-receiver may produce superheated steam of $515{ }^{\circ} \mathrm{C}$ and $10.7 \mathrm{MPa}$ with a solar heat absorbing efficiency of $86.55 \%$. The efficiency improvement compared to two-external cylindrical receivers is $3.2 \%$.

A Multi-Tube Cavity Receiver (MTCR) was optically modelled in [82]. The solar flux exhibits a significant non- uniformity, showing a maximum flux of $5.1 \cdot 10^{5} \mathrm{~W} / \mathrm{m}^{2}$ on the tubes. When considering the random effect on the solar flux distribution, it is a good practice to treat the tracking errors as the random errors of the tracking angles. Multipoint aiming strategy of tracking helps to homogenize the flux and reduce the energy mal-distribution among the tubes. The tubes absorb $65.9 \%$ of the energy. The optical loss can be reduced significantly by the cavity effect, especially when the coating absorptivity is relatively low.

Heliostats account for about $50 \%$ of the capital cost of CSP ST plants. In conventional heliostats with vertical pedestals and azimuth-elevation drives, the support structure contributes $40-50 \%$ of this cost due to heavy cantilever arms required by the large spanning structures. Additional costs are imposed by expensive, difficult to maintain, drive mechanisms. Ref. [83] shows that a tripod heliostat substantially addresses these shortcomings for heliostats with aperture areas of 62 to $100 \mathrm{~m}^{2}$. Raytracing simulations are included to estimate the performance penalties due to deformation under gravity and wind loads. The additional energy collection by a lessstiff, larger heliostat more than offsets the waste due to the greater deformation. The economics of CSP ST plants are strongly dependent on the cost of the heliostats rather than their optical performance. The cost of a tripod heliostat is reduced to $\$ 72 / \mathrm{m}^{2}$ which is less than half that of the conventional systems.

The thermal performance of a cavity receiver in a CSP ST plant that relies on the spatial relationship of its polyhedral geometric inner surfaces is studied in [84]. Based on model results, the thermal efficiency of the cavity receiver is shown to increase with the increase of incident 


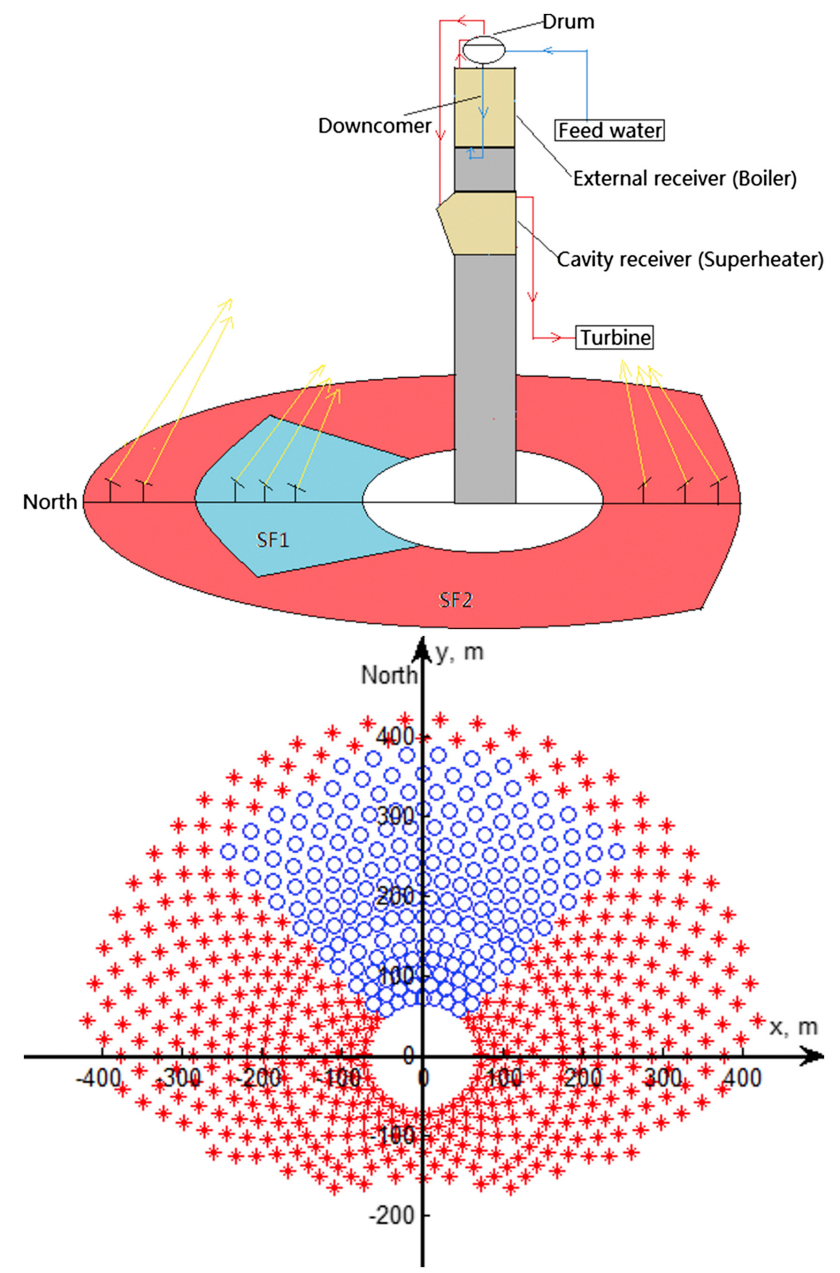

Fig. 4: Schematic diagram of the tower and heliostat field for the dual-receiver proposed in [81]. Reprinted from Applied Thermal Engineering, Vol. 91, Luo, Y., Du, X. and Wen, D., Novel design of central dual-receiver for solar power tower, Pages No. 1071-1081, Copyright (2015), with permission from Elsevier.

heat flux. When the width-depth ratio decreased, the cavity efficiency increased first and then decreased. The total heat loss of the receiver varied differently with the increase of the heat absorption area to the aperture area ratio.

The thermal efficiency of multi-cavity CSP ST receivers was modelled in [85]. There is an optimal aperture flux that maximizes the local efficiency. This optimum is constrained by the maximum receiver working temperature. For this aperture flux, the thermal efficiency, receiver temperature, and RF temperature are calculated for an optimized flux distribution. In the proposed case study, it was found that a RF with a minimum convection coefficient between 250 and $500 \mathrm{~W} / \mathrm{m}^{2} / \mathrm{K}$, permits to achieve a receiver thermal efficiency greater than $90 \%$.

An array of high temperature pressurized air based solar receivers for Brayton, recuperated, and combined
Brayton-Rankine cycles was investigated in [86]. The cluster of 500 solar receiver modules, attached to a hexagonshaped secondary concentrator and arranged side-by-side in a honeycomb-type structure following a spherical flyeye optical configuration, yield a peak solar energy to electricity efficiency of $37 \%$.

Ref. [87] studied beam-down concentrating solar tower (BCST). BCST are known for easy installation and maintenance as well as lower convection heat loss of the central receiver. A point-line-coupling-focus BCST system using linear Fresnel heliostat as the first stage concentrator (heliostat) and hyperboloid/ellipsoid reflector as the tower reflector is proposed. Theoretical investigation on the ray concentrating mechanism with two commonly used reflector structures, namely, hyperboloid and ellipsoid, indicate that the ellipsoid system is superior in terms of interception efficiency over the hyperboloid system due to smaller astigmatism at the central receiver aperture, especially at larger facet tracking error [87]. The ellipsoid reflector shows significantly lower tower reflector shading efficiency. This is the result of the larger tower reflector surface area compared to that of the hyperboloid reflector. The total optical efficiency of the hyperboloid system is always better than that of the ellipsoid system. This efficiency gap decreases as the ratio increases. The hyperboloid tower reflector is claimed to be more promising and practical for the system investigated.

Volumetric air receivers were studied in [88]. This component consists of a high temperature resistant cellular material which absorbs radiation and transfers the heat to an air flow which is fed from the ambient and from recirculated air. It is called volumetric, because the radiation may penetrate the "volume" of the receiver through the open, permeable cells of the material. In this way, a larger amount of heat transfer surface supports the solid to gaseous heat transfer in comparison to a tubular closed receiver. The heated air is directed to the steam generator of a conventional steam turbine system. Ref. [88] uses an advanced cellular metal honeycomb structure. It consists of winded pairs of flat and corrugated metal foils. Several variations of the pure linear honeycomb structure have been introduced to increase local turbulence and radial flow.

While some of these technologies may be easily implemented in future installations, those more sophisticated and innovative certainly require further studies. 


\subsection{Manufacturing and materials}

New materials and manufacturing processes are urgently needed to reduce costs and improve reliability and lifespan of current designs. New materials are also needed for operation of components with higher temperatures and with reduced heat losses to also improve efficiency.

While there is an abundant literature about new design of cycles, solar fields and receivers, TES system, and receiver and power block fluids, manufacturing processes and new materials are only marginally covered in the literature despite their huge impacts on costs and production of the CSP ST plants. Manufacturing of solar plant components is almost ignored.

Materials studies are mostly focused on the coating of the receiver. Solar receivers are presently mostly coated with a high sunlight absorptivity layer applied over the bare surface of the absorber receiver's tubes. Pyromark 2500 is the present standard coating. The coating enhances absorptivity and light-to-heat conversion. Ref. [89] studied the effect of the optical properties absorptivity and emissivity of these coatings on the thermal performance of a MS external receiver. Solar selective and non-selective coatings were analyzed and compared against the standard coating. The thermal efficiency increases up to $4 \%$ with the absorptivity of the coating. The emissivity has a very minor effect on the thermal performance of the receiver at its nominal working temperature. The efficiency only increases $0.6 \%$ when the emissivity of the coating decreases from 0.9 to 0.5 . Improving the absorptivity of a nonselective coating leads to higher thermal efficiency than using a selective coating for current MS temperatures. For superheated steam cavity receivers, the effect of using a selective coating is noticeable at temperatures greater than $500{ }^{\circ} \mathrm{C}$.

Ref. [90] also studied solar absorber coatings. The LCOE metric is used to attribute value to any hightemperature absorber coating. The LCOE gain efficiency is demonstrated on three different solar absorber coatings: Pyromark 2500, lanthanum strontium manganite oxide (LSM), and cobalt oxide $\left(\mathrm{CO}_{3} \mathrm{O}_{4}\right)$. These coatings were used in a 100 MWe central tower receiver. Depending on the coating properties, an optimal reapplication interval was found that maximizes the LCOE gain efficiency. Pyromark 2500 paint enables a higher LCOE gain efficiency (0.182) than both LSM (0.139) and $\mathrm{Co}_{3} \mathrm{O}_{4}(0.083)$. The solar absorptance is by far the most influential parameter. The cost-effectiveness of Pyromark can be outperformed by a coating that would have a high initial solar absorptance (>0.95), a low initial degradation rate $\left(<2 \cdot 10^{-6} \mathrm{cycle}^{-1}\right)$, and a low cost $(<\$ 500 \mathrm{k}$ per application).
A novel MoSi2-Si3N4 hybrid composite, Figure 5 was studied in [91]. The MoSi2-Si3N4 absorber deposited onto Inconel substrate and capped with a Si3N4/Al2O3 layer on top is a promising selective coating for receivers operating in air at temperatures about $600{ }^{\circ} \mathrm{C}$. Stacks with the Inconel/MoSi2-Si3N4/Si3N4/ Al2O3 structure on Inconel substrate show indeed good thermal stability in air.

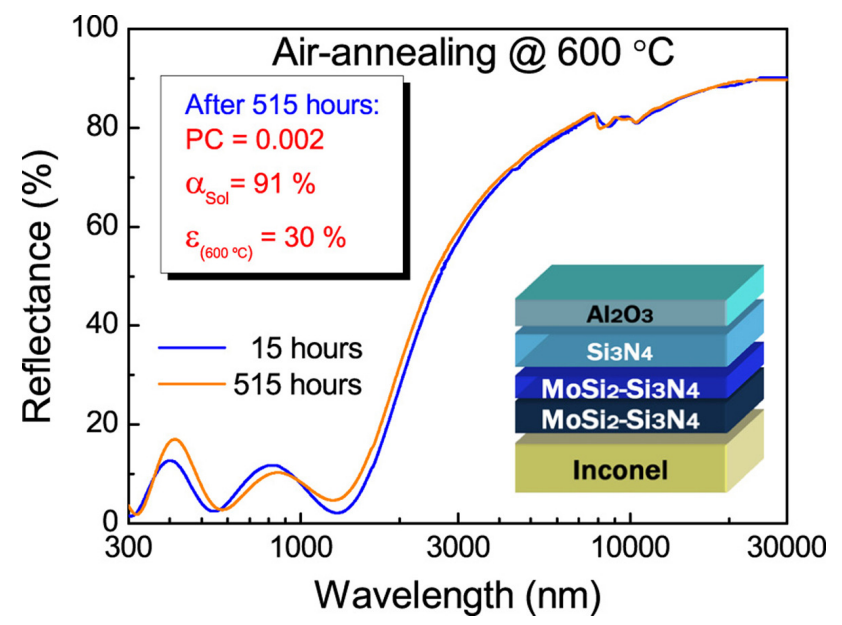

Fig. 5: Reflectance of new coating from Ref. [91]. Reprinted from Solar Energy Materials and Solar Cells, Vol. 174, Rodríguez-Palomo, A., Céspedes, E., Hernández-Pinilla, D. and Prieto, C., Hightemperature air-stable solar selective coating based on MoSi 2-Si 3 N 4 composite, Pages No. 50-55, Copyright (2018), with permission from Elsevier.

\subsection{Integrated solar combined cycle systems}

Here we report on the integration of CSP ST with CCGT or other plants, such as desalination plants.

Despite current policies may favor the opportunity of integrating CSP ST with CCGT, as explained in a prior section we do not believe CSP ST should be coupled to the burning of fossil fuels. While the use of NG in a boiler that supplement the solar field in the production of steam is common practice but it is not the best one as NG could be better used at double the thermal efficiency in a CCGT plant, it is more interesting opportunity to consider even if still questionable the coupling of a CSP ST plant with a CCGT plant.

Integrated solar combined cycle systems (ISCCS) are reviewed in Ref. [92]. ISCCS consist of three major components, CCGT, ST steam generator and solar field. The study indicates that very limited research has been directed so far toward the development of ISCCS with ST. Most of the 
ISCCS plants in operation today employ the PT technology. No known commercial ST ISCCS plant is operational in 2015. The study of ISCCS with ST is therefore an area of potential improvements still unexplored.

CSP PT and CSP ST coupled to a CCGT were modelled in [93]. The solar Rankine cycle is a single reheat regenerative Rankine cycle. The CCGT plant features a commercial gas turbine, with a dual pressure heat recovery steam generator. MS is the fluid to transfer heat to the water/steam of the solar Rankine cycle. Synthetic oil is used in the CCGT plant. The CSP ST has a higher collection efficiency than the CSP PT. The combined cycle is more efficient than the solar Rankine cycle. The CCGT plant coupled with a CSP $\mathrm{ST}$ is found to deliver the highest annual solar-to-electric efficiency of $21.8 \%$.

As the integration of renewables with conventional power sources is presently discouraged, it is not expected that power plant burning fossil fuels will be integrated with solar fields, even if this is by far the best opportunity to convert solar thermal energy in electricity.

While integration of CSP ST with CCGT does not make too much sense, there is certainly the scope of integrating CSP ST with Multi-effect desalination (MED) to produce electricity and clean water in remote areas. As power and water supply are the two major issues humanity will face during this century, a robust growth of CSP around the world may be integrated with desalination for the next renewable energy breakthrough [94].

In desalination, seawater is separated into a low concentration of salts freshwater stream and a high concentration of salts brine. The most relevant desalination technologies are thermal desalination and membrane desalination. Thermal desalination utilizes heat, often by steam, to change phase of the seawater from liquid to vapor. Membrane desalination utilizes pressure, and hence electricity driven pumps, to force water through a semipermeable membrane. In general, membrane desalination has advantages in terms of energy requirements and it is preferred where salinity is not very high. Seawater reverse osmosis (SWRO) membrane processes require less energy than multi-effect distillation (MED) thermal processes. However, Ref. [95] suggests that, for several locations, for example the Arabian Gulf, CSP plus MED may require $4 \%$ to $11 \%$ less input energy than CSP plus SWRO. This introduces an interesting opportunity for selected locations where MED may be competitive with SWRO. While SWRO does not need any integration of the desalination plant with the CSP plant, as the electricity needed can be produced everywhere, MED may be easily and conveniently integrated with a CSP saving the condenser costs.
MED produces high quality water from sea or brackish water. Concentration of total dissolved solids (TDS) is $25 \mathrm{mg} / \mathrm{l}$ or less. MED units range from about $100 \mathrm{~m}^{3} /$ day up to $36,400 \mathrm{~m}^{3} /$ day. While single units may be utilized in smaller volume applications, multiple units may be combined to further increase capacity [94].

In desert installations, far from the coast, the condenser is air cooled, and this limits the expansion of steam in turbine. While in coastal locations the condenser may certainly be, water cooled for better performances of the plant, alternatively, the condenser may also be replaced by a MED thermal desalination module. The steam generated is superheated to $380{ }^{\circ} \mathrm{C}$ to $580^{\circ} \mathrm{C}$ and the steam temperature for the MED is not higher than $135^{\circ} \mathrm{C}$ [94]. Hence, the steam has sufficient energy to produce electricity before entering the MED. If power is the main product, a water condenser may work better. However, where water is more precious than power, and MED is competitive with SWRO, integration of CSP ST with MED is a local renewable energy break-through.

Ref. [96] proposed solar thermal sea water desalination, however adopting multi-stage flash evaporation (MSF) rather than MED. The theoretical study considers a ST with a volumetric solar receiver, a power cycle water/steam Rankine, MS as the receiver fluid, MS TES plus the MSF. The seawater is heated by the saturated steamwater mixture coming from the steam turbine. This eliminates the condenser. Considering the advantages MED has vs. MSF [94], presently the primary thermal desalination option, the advantages mentioned in [96] will be further strengthen when using MED.

\subsection{Regionalization}

As a final area of concern, here we report on the improvement being sought in CSP ST technology by specializing the design for a specific geographical location. Places with lot of sun to make plausible CSP ST plant may have very different climate conditions. Proximity to coast, availability of land, orography of land, coupling to desalination, availability of NG, prevailing weather conditions, sand storms, wind load, rainfall, all play a key role to reshape one single design to match local conditions. Despite some design concepts may certainly be shared between many different CSP installations, regionalization plays a significant role in providing the sought outcomes in terms of performance, cost and life span of a plant.

The technical, financial and policy drivers and barriers for adopting CSP ST technologies in India were studied in [54]. Especially CSP ST with external cylindrical or cav- 
ity receivers with storage look promising. This technology is particularly relevant to the Jawaharlal Nehru National Solar Mission (JNNSM) aimed at achieving grid-connected solar power of 1800 MW by 2022.

Ref. [97] reviews the CSP plants installed in India and discusses the growth of the electricity generated by CSP in India, with targets grown to 100,000 MW by 2022.

The design and construction of a CSP ST demonstration plant in Saudi Arabia, an area of extreme solar intensity and temperatures, was reported in [98]. The solar receiver was made of alloy steel. Ten heliostats were chosen, featuring two motors were used to control the heliostat rotational and elevation movements. The thermal fluid was a MS mixture $60 \% \mathrm{NaNO}_{3}$ and $40 \% \mathrm{KNO}_{3}$. Cold and hot storage tanks were manufactured from steel insulated with calcium silicate from all sides. A one-meter high and one and a half-meter diameter cylindrical vessel was adopted for each of the cold and hot tanks. The design thermal power was $13 \mathrm{~kW}$. The thermal power released by the MS was $12.31 \mathrm{~kW}$. The thermal power transferred to the water/steam was $11.26 \mathrm{~kW}$. The work proves the value of small demonstration plants. Small demonstration plant is needed for regionalization in every location where conditions may differ considerably from the areas of well-established designs to perform a proper regionalization of the design.

The energy and exergy analyses of $\mathrm{sCO}_{2}$ recompression Brayton cycles of Ref. [72] is performed for different locations in Saudi Arabia. The exercise returns a ranking by location based on the selected CSP ST configuration.

Ref. [99] simulated the behavior of the Spanish GEMASOLAR plant under different climates. The analysis is performed for different locations of mainland China. An estimation of both annual energy production and return of the investment was provided. Simulations were made with and without hybridization with combustion of fossil fuels and with same or modified nominal power. Annual overall efficiencies were about $14 \%$ for the $20 \mathrm{MW}$ power plant (GEMASOLAR nominal power). Down-scaled plants were able of maintaining an efficiency of $14.97 \%$ for a $10 \mathrm{MW}$ power plant.

Ref. [100] compares under the Algerian climate a Rankine cycle with a tubular water/steam receiver and a Brayton cycle with volumetric air receiver. The tubular receiver Rankine cycle is economically slightly disadvantaged vs. the volumetric air receiver Brayton cycle, but it works better especially under lower solar radiation intensity. The GT requires higher operating temperatures which are usually difficult to reach throughout the year.

\section{Conclusions}

Our analysis builds on actual data of costs and operation of CSP ST facilities.

There are only two CSP ST plants of capacity more than $100 \mathrm{MW}$ operational in the world. The largest one, the 377 MW capacity ISEGS, with no TES, has not produced more than 703,039 MWh/year in the $3^{\text {rd }}$ year of life (2016), up from the 419,085 MWh/year of the $1^{\text {st }}$ year of life (2014), despite the combustion of huge amounts of NG, still $1,290,308 \mathrm{MMBtu}$ in the $3^{\text {rd }}$ year of life (2016). The planned electricity generation was 1,079,232 MWh/year since 2014. Actual construction cost has been 6,085 \$/kW (2017 values). The other plant, the 110 MW Crescent Dunes facility, with TES, has produced in 2016 only 127,308 MWh/year vs. the planned 500,000 MWh/year. Actual construction cost has been 9,227 \$/kW (2017 values).

The electricity production and the reliability of the plant have been so far worse than the expected. Additionally, the costs have been much larger than what was planned. The real-world experience thus casts considerable doubts on the number being proposed for the CSP ST technology by expert panels and the literature. The CSP ST plant technology is still very far from the standards of conventional power plants in the power industry, where the actual costs and performances are usually close to the planned values. More experience must be gathered to proper develop a technology that appears to be still in its infancy.

Having said that, there are certainly many development trends being sought that even if not game changers can make the CSP ST technology much more competitive at least vs. other renewables, wind or solar photovoltaics. As actual numbers are very far from plans, we analyze all these technology updates being sought with the due skepticism. The current trends in the development of CSP ST installations have been reviewed. Improvements are being sought for efficiency of plant, installation cost, life-span and operation cost. Materials and manufacturing processes, design of solar field and receiver, including fluids, cycle and materials, optimal management of daily and seasonal operation of the plant, new TES concepts, integration of solar plant with thermal desalination, integration of solar plant with CCGT installations and finally, specialization and regionalization of the project specification, are the key areas of progress of CSP ST technology.

While it is expected that CSP ST installations will grow considerably in the next few years, there is not yet a better solution all-inclusive than the use of MS as RF and TES fluid, with classic solar field heliostats and receivers, driv- 
ing a water/steam superheated Rankine cycle steam cycle. Manufacturing is a major keyword to cover. The different alternatives that are presently under study at different stages of development may only progress slowly, benefiting from real world experiences requiring time rather than simulations or laboratory experiments. Cost of plants are not expected to reduce drastically, even if convergence on few selected designs of heliostats and receivers could be beneficial to their improvement and cost reduction, with manufacturing of components in large scale and significant feed-backs from real world operation expected to be a major driver of the developments.

Acknowledgement: The authors received no funding.

Conflicts of Interest: The authors declare no conflict of interest.

Authors' contributions: The authors equally contributed to the review of the papers and the writing of the manuscript.

\section{Symbols}

\begin{tabular}{ll}
\hline$\eta$ & efficiency \\
$\epsilon$ & capacity factor \\
$\mathrm{E}$ & electric energy \\
$\mathrm{P}$ & electric power \\
$\mathrm{Q}$ & thermal energy \\
$\mathrm{SCO}_{2}$ & supercritical carbon dioxide \\
\hline
\end{tabular}

\section{Acronyms}

\begin{tabular}{ll}
\hline BCST & beam-down concentrating solar tower \\
CSP & concentrated solar power \\
CCGT & combined cycle gas turbine \\
GT & gas turbine \\
ISCCS & Integrated solar combined cycle system \\
ISEGS & Ivanpah Solar Electric Generating System \\
LCOE & Levelized Cost of Electricity \\
MED & multi effect distillation \\
MS & molten salt \\
MTCR & Multi Tube Cavity Receiver \\
NG & natural gas \\
PT & Parabolic Trough \\
PV & photovoltaic \\
RF & receiver fluid \\
RMCI & Recompression with Main Compression Intercooling \\
SEGS & Solar Energy Generating Systems \\
\hline
\end{tabular}

\begin{tabular}{ll}
\hline ST & Solar Tower \\
SWRO & sea water reverse osmosis \\
TCES & thermochemical energy storage \\
TES & thermal energy storage \\
TETR & Traditional External Tubular Receiver \\
VVR & Variable Velocity Receiver \\
\hline
\end{tabular}

\section{References}

[1] Romero-Alvarez, M. and Zarza, E., Concentrating solar thermal power. Handbook of energy efficiency and renewable energy, 2007:21-1.

[2] Müller-Steinhagen, $\mathrm{H}$. and Trieb, F., Concentrating solar power. A review of the technology. Ingenia Inform QR Acad Eng, 2004, 18:43-50.

[3] Zhang, H.L., Baeyens, J., Degrève, J. and Cacères, G., Concentrated solar power plants: Review and design methodology. Renewable and Sustainable Energy Reviews, 2013, 22:466481.

[4] Barlev, D., Vidu, R. and Stroeve, P., Innovation in concentrated solar power. Solar Energy Materials and Solar Cells, 2011, 95(10):2703-2725.

[5] Winter, C.J., Sizmann, R.L. and Vant-Hull, L.L. eds., 2012. Solar power plants: fundamentals, technology, systems, economics. Springer Science \& Business Media.

[6] Sawin, J.L. and Martinot, E., Renewables bounced back in 2010, finds REN21 global report. Renewable Energy World, 2011, 14(5):29. www.renewableenergyworld.com/ articles/print/volume-14/issue-5/solar-energy/renewablesbounced-back-in-2010-finds-ren21-global-report.html, Retrieved November 9, 2017.

[7] Renewable Energy Policy Network for the 21st Century (REN21), Renewables Global Status Report 2017, 2017. www.ren21.net/wp-content/uploads/2017/06/17-8399_ GSR_2017_Full_Report_0621_Opt.pdf, Retrieved November 8, 2017.

[8] Boretti, A., Concentrated Solar Power Plants Capacity Factors: A Review, Nonlinear Approaches in Engineering Applications Energy: Vibrations, and Modern Applications, Liming Dai, Eds., Reza N. Jazar, Springer, New York, 2017.

[9] Lilliestam, J., After the Desertec hype: is concentrating solar power still alive?, September 2017. www.ethz.ch/en/newsand-events/eth-news/news/2017/09/concentrating-solarpower.html, Retrieved November 9, 2017.

[10] International Energy Agency, 2016 Key world energy statistics, 2016. www.iea.org/publications/freepublications/ publication/KeyWorld2016.pdf, Retrieved November 8, 2017.

[11] Energy Information Administration, Electricity data browser Net generation for all sectors - United States. www.eia.gov/ electricity/data/browser, Retrieved November 9, 2017.

[12] National Renewable Energy Laboratory (NREL), Concentrating Solar Power Projects - Ivanpah Solar Electric. www.nrel.gov/ csp/solarpaces/project_detail.cfm/projectID $=62$, Retrieved November 8, 2017.

[13] Energy Information Administration, Electricity data browser - Plant Level Data Ivanpah 1. www.eia.gov/electricity/data/ browser/\#/plant/57074/, Retrieved November 9, 2017. 
[14] Energy Information Administration, Electricity data browser - Plant Level Data Ivanpah 2. www.eia.gov/electricity/data/ browser/\#/plant/57073/, Retrieved November 9, 2017.

[15] Energy Information Administration, Electricity data browser - Plant Level Data Ivanpah 3. www.eia.gov/electricity/data/ browser/\#/plant/57075/, Retrieved November 9, 2017.

[16] del Río, P., Peñasco, C. and Mir-Artigues, P., An overview of drivers and barriers to concentrated solar power in the European Union. Renewable and Sustainable Energy Reviews, 2018, 81:1019-1029.

[17] de Souza, L.E.V. and Cavalcante, A.M.G., Concentrated Solar Power deployment in emerging economies: The cases of China and Brazil. Renewable and Sustainable Energy Reviews, 2017, 72:1094-1103.

[18] National Renewable Energy Laboratory (NREL), Power Tower Projects, www.nrel.gov/csp/solarpaces/power_tower.cfm, Retrieved November 9, 2017.

[19] ABENGOA SOLAR, Concentrating Solar Power: State of the Art. ARPA-E Solar Beyond Grid Parity: Spectrum-Efficient Solar Energy for Dispatchable Electricity or Fuels Workshop, Boulder, CO April 11-12 2013. www.arpa-e.energy.gov/sites/ default/files/documents/files/SolarBeyondGridParity_ Erickson.pdf retrieved November 9, 2017.

[20] Margolis, R., Coggeshall, C. and Zuboy, J., SunShot vision study. US Dept. of Energy, 2012.

[21] Kearney, D. and Herrmann, U., Engineering evaluation of a molten salt heat transfer fluid in a parabolic trough solar field. National Renewal Energy Laboratoy, 2006.

[22] Feldhoff, J.F., Schmitz, K., Eck, M., Schnatbaum-Laumann, L., Laing, D., Ortiz-Vives, F. and Schulte-Fischedick, J., Comparative system analysis of direct steam generation and synthetic oil parabolic trough power plants with integrated thermal storage. Solar Energy, 2012, 86(1): 520-530.

[23] Bendt, P., Rabl, A., Gaul, H.W. and Reed, K.A., Optical analysis and optimization of line focus solar collectors (No. NREL/TR-34-92). National Renewable Energy Laboratory (NREL), Golden, CO, 1979.

[24] Reilly, H.E. and Kolb, G.J., An evaluation of molten-salt power towers including results of the solar two project (No. SAND2001-3674). Sandia National Labs., Albuquerque, NM (US); Sandia National Labs., Livermore, CA (US), 2007.

[25] Radosevich, L.G., Final Report on the Power Production Phase of the 10 MWe Solar Thermal Central Receiver Pilot Plant, SAND87-8022. Sandia National Laboratories, Albuquerque, NM, 1988.

[26] Thermoflow, Inc., "Thermoflow". www.thermoflow.com/, Retrieved November 9, 2017.

[27] National renewable Energy Laboratory, Concentrating Solar Power Projects by Project Name. www.nrel.gov/csp/ solarpaces/by_project.cfm, Retrieved November 9, 2017.

[28] Energy Information Administration. Electricity data browser - Plant Level Data. www.eia.gov/electricity/data/browser/, Retrieved November 9, 2017.

[29] Kuravi, S., Trahan, J., Goswami, D.Y., Rahman, M.M. and Stefanakos, E.K., Thermal energy storage technologies and systems for concentrating solar power plants. Progress in Energy and Combustion Science, 2013, 39(4):285-319.

[30] Sioshansi, R. and Denholm, P., The value of concentrating solar power and thermal energy storage. IEEE Transactions on Sustainable Energy, 2010, 1(3):173-183.
[31] Gil, A., Medrano, M., Martorell, I., Lázaro, A., Dolado, P., Zalba, B. and Cabeza, L.F., State of the art on high temperature thermal energy storage for power generation. Part 1-Concepts, materials and modellization. Renewable and Sustainable Energy Reviews, 2010, 14(1):31-55.

[32] Medrano, M., Gil, A., Martorell, I., Potau, X. and Cabeza, L.F., State of the art on high-temperature thermal energy storage for power generation. Part 2-Case studies. Renewable and Sustainable Energy Reviews, 2010, 14(1):56-72.

[33] Cavallaro, F., Fuzzy TOPSIS approach for assessing thermalenergy storage in concentrated solar power (CSP) systems. Applied Energy, 2010, 87(2):496-503.

[34] Price, H., Lupfert, E., Kearney, D., Zarza, E., Cohen, G., Gee, R. and Mahoney, R., Advances in parabolic trough solar power technology. Journal of solar energy engineering, 2002, 124(2):109-125.

[35] National Renewable Energy Laboratory (NREL), Integrating Variable Renewable Energy Into the Grid. NREL/FS-6A2063033, May 2015. www.nrel.gov/docs/fy15osti/63033.pdf, Retrieved November 9, 2017.

[36] International Renewable Energy Agency (IRENA), Renewable Energy Integration in Power Grids. April 2015. www.irena. org/DocumentDownloads/Publications/IRENA-ETSAP_Tech_ Brief_Power_Grid_Integration_2015.pdf, Retrieved November 9, 2017.

[37] American Physical Society, Integrating Renewable Electricity on the Grid. November 2011, www.aps.org/policy/reports/ popa-reports/upload/integratingelec.pdf, Retrieved November $9,2017$.

[38] Larson, A., World's Most-Efficient Combined Cycle Plant: EDF Bouchain, Power magazine, September 1, 2017, www. powermag.com/worlds-most-efficient-combined-cycleplant-edf-bouchain/, retrieved November 9, 2017.

[39] General Electric Company, POWERING A NEW RECORD AT EDF. 9HA.01 SETS EFFICIENCY WORLD RECORD, August 2016. www.gepower.com/content/dam/gepower-pgdp/global/en_ US/documents/product/gas\%20turbines/White\%20Paper/ gea32885-bouchain-whitepaper-final-aug-2016.pdf, retrieved November 9, 2017.

[40] Overton, T., Gas Combined Cycle Capacity Factors Beat Coal for First Time Ever, Power magazine, 04/11/2016. www.powermag.com/gas-combined-cycle-capacity-factorsbeat-coal-for-first-time-ever/, retrieved November 9, 2017.

[41] Douglas, I., ISEGS Order Approving Petition to Amend, 15 September 2014. docketpublic.energy. ca.gov/PublicDocuments/07-AFC-05C/TN203064_ 20140915T132932_ISEGS_Order_Approving_Petition_to_ Amend.pdf, Retrieved November 9, 2017.

[42] Danelski, D., It's not easy being green: Ivanpah solar plant near Nevada burns much natural gas, making it a greenhouse gas emitter under state law. Orange County Register. Santa Ana, California. 21 October 2015. www.ocregister.com/2015/ $10 / 21$ /its-not-easy-being-green-ivanpah-solar-plant-nearnevada-burns-a-lot-of-natural-gas-making-it-a-greenhousegas-emitter-under-state-law/, Retrieved November 9, 2017.

[43] Price, H. and Kearney, D., Reducing the cost of energy from parabolic trough solar power plants. In International Solar Energy Conference. Hawaii Island, Hawaii, January 2003. National Renewable Energy Laboratory NREL/CP-550-33208. [44] National Renewable Energy Laboratory (NREL), Concen- 
trating Solar Power Projects - Crescent Dunes Solar Energy, www.nrel.gov/csp/solarpaces/project_detail.cfm/projectID= 60, Retrieved November 8, 2017.

[45] Energy Information Administration, Electricity data browser - Plant Level Data Crescent Dunes Solar Energy, www.eia. gov/electricity/data/browser/\#/plant/57275/, Retrieved November 9, 2017.

[46] Energy Information Administration (EIA), Construction cost data for electric generators installed in 2015. May 2017. www. eia.gov/electricity/generatorcosts/, retrieved November 9 , 2017.

[47] Energy Information Administration (EIA), Cost and Performance Characteristics of New GeneratingTechnologies, Annual Energy Outlook 2017. January 2017. www.eia.gov/ outlooks/aeo/assumptions/pdf/table_8.2.pdf, retrieved November 9, 2017.

[48] National Renewable Energy Laboratory (NREL), Concentrating Solar Power Projects - Solana Generating Station www.nrel.gov/csp/solarpaces/project_detail.cfm/projectID= 23, Retrieved November 8, 2017.

[49] Energy Information Administration, Electricity data browser - Plant Level Data Solana https://www.eia.gov/electricity/ data/browser/\#/plant/56812, Retrieved November 9, 2017.

[50] National Renewable Energy Laboratory (NREL), Concentrating Solar Power Projects - Solar Electric Generating Station IX. www.nrel.gov/csp/solarpaces/project_detail.cfm/project ID= 36, Retrieved November 8, 2017.

[51] Energy Information Administration, Electricity data browser - Plant Level Data SEGS IX www.eia.gov/electricity/data/ browser/\#/plant/10446/, Retrieved November 9, 2017.

[52] Pfenninger, S., Gauché, P., Lilliestam, J., Damerau, K., Wagner, F. and Patt, A., Potential for concentrating solar power to provide baseload and dispatchable power. Nature Climate Change, 2014, 4(8):689-692.

[53] Lilliestam J, Labordena M, Patt A, \& Pfenninger S., Empirically observed learning rates for concentrating solar power and their responses to regime change. Nature Energy, 2017, 2:17094.

[54] Srilakshmi, G., Venkatesh, V., Thirumalai, N.C. and Suresh, N.S., Challenges and opportunities for Solar Tower technology in India. Renewable and Sustainable Energy Reviews, 2015, 45:698-709.

[55] Hoffschmidt, B., Receivers for Solar Tower Systems. CNRS 2014 SFERA School, June 25-27, 2014, Font Romeu, France. elib.dlr.de/94540/1/SFERA2014_SolarTowerReceivers_final. pdf, Retrieved November 9, 2017.

[56] Vignarooban, K., Xu, X., Arvay, A., Hsu, K. and Kannan, A.M., Heat transfer fluids for concentrating solar power systems-a review. Applied Energy, 2015, 146:383-396.

[57] Liu, M., Belusko, M., Tay, N.S. and Bruno, F., Impact of the heat transfer fluid in a flat plate phase change thermal storage unit for concentrated solar tower plants. Solar Energy, 2014, 101:220-231.

[58] Pelay, U., Luo, L., Fan, Y., Stitou, D. and Rood, M., Thermal energy storage systems for concentrated solar power plants. Renewable and Sustainable Energy Reviews, 2017, 79:82100.

[59] González-Roubaud, E., Pérez-Osorio, D. and Prieto, C., Review of commercial thermal energy storage in concentrated solar power plants: Steam vs. molten salts. Renewable and
Sustainable Energy Reviews, 2017, 80:133-148.

[60] Zhang, H., Benoit, H., Perez-Lopèz, I., Flamant, G., Tan, T. and Baeyens, J., High-efficiency solar power towers using particle suspensions as heat carrier in the receiver and in the thermal energy storage. Renewable Energy. 2017.

[61] Alexopoulos, S. and Hoffschmidt, B., Advances in solar tower technology. Wiley Interdisciplinary Reviews: Energy and Environment, 2017, 6(1).

[62] Peng, X., Root, T.W. and Maravelias, C.T., Storing solar energy with chemistry: the role of thermochemical storage in concentrating solar power. Green Chemistry, 2017, 19(10):2427-2438.

[63] Tescari, S., Singh, A., Agrafiotis, C., de Oliveira, L., Breuer, S., Schlögl-Knothe, B., Roeb, M. and Sattler, C., Experimental evaluation of a pilot-scale thermochemical storage system for a concentrated solar power plant. Applied Energy, 2017, 189:66-75.

[64] Pacheco, J.E., Wolf, T. and Muley, N., Incorporating Supercritical Steam Turbines Into Advanced Molten-Salt Power Tower Plants: Feasibility and Performance. Sandia National Laboratories, Albuquerque, NM, Report No. SAN2013-1960, 2013.

[65] Turchi, C.S., Ma, Z., Neises, T.W. and Wagner, M.J., Thermodynamic study of advanced supercritical carbon dioxide power cycles for concentrating solar power systems. Journal of Solar Energy Engineering, 2013, 135(4):041007.

[66] Zheng, H., Yu, X., Su, Y., Riffat, S. and Xiong, J., Thermodynamic analysis of an idealised solar tower thermal power plant. Applied Thermal Engineering, 2015, 81:271-278.

[67] Schmitt, J., Wilkes, J., Allison, T., Bennett, J., Wygant, K. and Pelton, R., Lowering the Levelized Cost of Electricity of a Concentrating Solar Power Tower with a Supercritical Carbon Dioxide Power Cycle. In ASME Turbo Expo 2017: Turbomachinery Technical Conference and Exposition (pp. V009T38A028V009T38A028). American Society of Mechanical Engineers, 2017, June.

[68] Stein, W.H. and Buck, R., Advanced power cycles for concentrated solar power. Solar Energy, 2017, 152:91-105.

[69] Binotti, M., Astolfi, M., Campanari, S., Manzolini, G. and Silva, P., Preliminary assessment of sCO 2 cycles for power generation in CSP solar tower plants. Applied Energy.

[70] Wang, K., He, Y.L. and Zhu, H.H., Integration between supercritical CO 2 Brayton cycles and molten salt solar power towers: A review and a comprehensive comparison of different cycle layouts. Applied Energy, 2017, 195:819-836.

[71] Rodríguez-Sánchez, M.R., Sánchez-González, A., GonzálezGómez, P.A., Marugán-Cruz, C. and Santana, D., Thermodynamic and economic assessment of a new generation of subcritical and supercritical solar power towers. Energy, 2017, 118:534-544.

[72] Atif, M. and Al-Sulaiman, F.A., Energy and exergy analyses of solar tower power plant driven supercritical carbon dioxide recompression cycles for six different locations. Renewable and Sustainable Energy Reviews, 2017, 68:153-167.

[73] Poživil, P. and Steinfeld, A., Integration of a Pressurized-Air Solar Receiver Array to a Gas Turbine Power Cycle for Solar Tower Applications. Journal of Solar Energy Engineering, 2017, $139(4)$, p.041007.

[74] Ho, C.K. and Iverson, B.D., Review of high-temperature central receiver designs for concentrating solar power. Renew- 
able and Sustainable Energy Reviews, 2014, 29:835-846.

[75] Rodríguez-Sánchez, M.R., Sánchez-González, A. and Santana, D., Feasibility study of a new concept of solar external receiver: variable velocity receiver. Applied Thermal Engineering. 2018. 128:335-344.

[76] Salomé, A., Chhel, F., Flamant, G., Ferrière, A. and Thiery, F., Control of the flux distribution on a solar tower receiver using an optimized aiming point strategy: Application to THEMIS solar tower. Solar Energy, 2013, 94:352-366.

[77] Carrizosa, E., Domínguez-Bravo, C.A., Fernández-Cara, E. and Quero, M., An optimization tool to design the field of a solar power tower plant allowing heliostats of different sizes. International Journal of Energy Research. 2017.

[78] Roldán, M.I., Fernández-Reche, J. and Ballestrín, J., Computational fluid dynamics evaluation of the operating conditions for a volumetric receiver installed in a solar tower. Energy, 2016, 94:844-856.

[79] Hoffschmidt, B., Tellez, F.M., Valverde, A., Fernańdez, J. and Fernańdez, V., Performance evaluation of the 200-kWth HiTRec-II open volumetric air receiver, 2003. Journal of Solar Energy Engineering, 125(1):87-94.

[80] He, Y.L., Cui, F.Q., Cheng, Z.D., Li, Z.Y. and Tao, W.Q., Numerical simulation of solar radiation transmission process for the solar tower power plant: from the heliostat field to the pressurized volumetric receiver. Applied Thermal Engineering, 2013, 61(2):583-595.

[81] Luo, Y., Du, X. and Wen, D., Novel design of central dualreceiver for solar power tower. Applied Thermal Engineering, 2015, 91:1071-1081.

[82] Qiu, Y., He, Y.L., Li, P. and Du, B.C., A comprehensive model for analysis of real-time optical performance of a solar power tower with a multi-tube cavity receiver. Applied Energy, 2017, 185:589-603.

[83] Thalange, V.C., Dalvi, V.H., Mahajani, S.M., Panse, S.V., Joshi, J.B. and Patil, R.N., Design, optimization and optical performance study of tripod heliostat for solar power tower plant. Energy, 2017, 135:610-624.

[84] Deng, Q., Xiao, X., Hao, Y., Wang, Q., Hu, T. and Wang, Y., Heat transfer performance evaluation of a large-size cavity receiver in the solar power tower plant based on angle factors. Solar Energy, 2017, 148:78-86.

[85] Fleming, A., Folsom, C., Ban, H. and Ma, Z., 2017. A general method to analyze the thermal performance of multi-cavity concentrating solar power receivers. Solar Energy, 2017, 150:608-618

[86] Hischier, I., Poživil, P. and Steinfeld, A., Optical and Thermal Analysis of a Pressurized-Air Receiver Cluster for a 50 MWe Solar Power Tower. Journal of Solar Energy Engineering, 2015, 137(6), p.061002.

[87] Li, X., Lin, M., Dai, Y. and Wang, C.H., Comparison-based optical assessment of hyperboloid and ellipsoid reflectors in a beam-down solar tower system with linear Fresnel heliostats. Journal of Solar Energy Engineering, 2017, 139(6):061003.

[88] Pabst, C., Feckler, G., Schmitz, S., Smirnova, O., Capuano, R., Hirth, P. and Fend, T., Experimental performance of an advanced metal volumetric air receiver for Solar Towers. Renewable Energy, 2017, 106:91-98.

[89] López-Herraiz, M., Fernández, A.B., Martinez, N. and Gallas, M., Effect of the optical properties of the coating of a concentrated solar power central receiver on its thermal efficiency.
Solar Energy Materials and Solar Cells, 2017, 159:66-72.

[90] Boubault, A., Ho, C.K., Hall, A., Lambert, T.N. and Ambrosini, A., Durability of solar absorber coatings and their costeffectiveness. Solar Energy Materials and Solar Cells, 2017, 166:176-184.

[91] Rodríguez-Palomo, A., Céspedes, E., Hernández-Pinilla, D. and Prieto, C., High-temperature air-stable solar selective coating based on MoSi 2-Si 3 N 4 composite. Solar Energy Materials and Solar Cells, 2018, 174:50-55.

[92] Okoroigwe, E. and Madhlopa, A., An integrated combined cycle system driven by a solar tower: A review. Renewable and Sustainable Energy Reviews, 2016, 57:337-350.

[93] Franchini, G., Perdichizzi, A., Ravelli, S. and Barigozzi, G., A comparative study between parabolic trough and solar tower technologies in Solar Rankine Cycle and Integrated Solar Combined Cycle plants. Solar Energy, 2013, 98:302-314.

[94] Zachary, J. and Layman, C.M., 2010. Adding Desalination to Solar Hybrid and Fossil Plants. Power, 154(5).

[95] Trieb, F. and Müller-Steinhagen, H., 2008. Concentrating solar power for seawater desalination in the Middle East and North Africa. Desalination, 220(1-3):165-183.

[96] Demir, M.E. and Dincer, I., Development and analysis of a new integrated solar energy system with thermal storage for fresh water and power production. International Journal of Energy Research. 2017, DOI: 10.1002/er.3846.

[97] Kumar, A., Prakash, O. and Dube, A., A review on progress of concentrated solar power in India. Renewable and Sustainable Energy Reviews, 2017, 79:304-307.

[98] Abu-Hamdeh, N.H. and Alnefaie, K.A., Design considerations and construction of an experimental prototype of concentrating solar power tower system in Saudi Arabia. Energy Conversion and Management, 2016, 117:63-73.

[99] Amadei, C.A., Allesina, G., Tartarini, P. and Yuting, W., Simulation of GEMASOLAR-based solar tower plants for the Chinese energy market: Influence of plant downsizing and location change. Renewable energy, 2013, 55:366-373.

[100] Yamani, N., Khellaf, A., Mohammedi, K. and Behar, O., Assessment of solar thermal tower technology under Algerian climate. Energy, 2017, 126:444-460.

[101] US Inflation Calculator, www.usinflationcalculator.com/, Retrieved November 9, 2017.

[102] Williges, K., Lilliestam, J. \& Patt, A. Making concentrated solar power competitive with coal: the costs of a European feed-in tariff. Energy Policy, 2010, 38:3089-3097.

[103] Neij, L. Cost development of future technologies for power generation - A study based on experience curves and complementary bottom-up assessments. Energy Policy, 2008, 36:2200-2211.

[104] Viehbahn, P., Lechon, Y. \& Trieb, F. The potential role of concentrated solar power (CSP) in Africa and Europe. Energy Policy, 2011, 39, 4420-4430.

[105] Energy Efficiency and Renewable Energy (EERE), Renewable Energy Technology Characterizations - December 1997 Solar Parabolic Trough. www1.eere.energy.gov/ba/pba/ pdfs/solar_trough.pdf, Retrieved November 9, 2017.

[106] Boretti, A., Cost and Production Analysis of the Latest Solar Thermal and Solar Photovoltaics Electricity Plants in the United States, 2018, submitted paper. 